\title{
Copulatory and Postcopulatory Sexual Selection in Primates
}

\author{
Alan F. Dixson \\ School of Biological Sciences, Victoria University of Wellington, Wellington, New Zealand
}

\section{Keywords}

Postcopulatory sexual selection - Copulatory behaviour - Sperm competition .

Cryptic female choice $\cdot$ Mammals $\cdot$ Human evolution

\begin{abstract}
Many aspects of primate reproductive anatomy and physiology have been influenced by copulatory and postcopulatory sexual selection, especially so in taxa where multiple-partner matings by females result in the sperm of rival males competing for access to a given set of ova (sperm competition). However, the female reproductive system also exerts profound effects upon sperm survival, storage and transport, raising the possibility that female traits influence male reproductive success (via cryptic female choice). Current knowledge of sperm competition and cryptic choice in primates and other mammals is reviewed here. The relevance of these comparative studies to our understanding of human reproduction and evolution is discussed. @ $2018 \mathrm{~S}$. Karger AG, Basel
\end{abstract}

Having carefully weighed, to the best of my ability, the various arguments that have been advanced against the principle of sexual selection, I remain firmly convinced of its truth.

Charles Darwin

Darwin wrote these words shortly before his death, in 1882. At that time, and for almost a century afterwards, sexual selection was considered to operate solely with respect to events that occur before copulation. Intermale competition for access to females, and female mate choices for the most attractive males were viewed as the drivers by which sexual selection influences reproductive success. However, we now know that sexual selection also results from events that occur both during and after the act of mating. These fresh insights, concerning sexual selection by sperm compe-

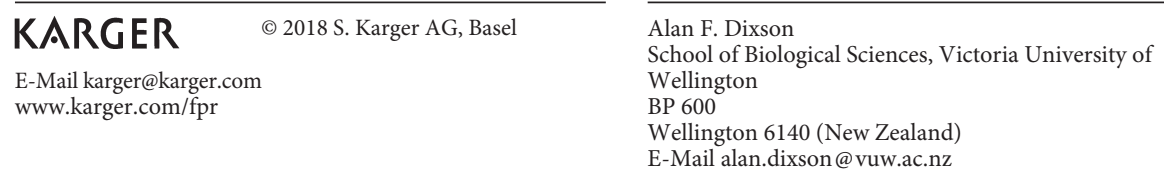


tition and cryptic female choice, were initially the products of research conducted on insects. The discovery of sperm competition [Parker, 1970] thus owed much to the yellow dung fly (Scathophaga stercoraria), whilst the concept of cryptic female choice derived from work originally conducted on scorpion flies (Harpobittacus nigriceps [Thornhill, 1983]).

Sperm competition concerns the competition that occurs between the gametes of 2, or more, rival males "for access to a given set of ova" [Parker, 1998]. However, it is the female's reproductive tract which constitutes the arena for sperm competition. In primates, as in most animals, spermatozoa must traverse multiple anatomical and physiological barriers within the female reproductive system before encountering her ova. Therefore, the female's anatomy and physiology might also influence the fate of gametes from rival males in different ways; it is this hidden potential which constitutes cryptic female choice [Eberhard, 1985, 1996, 2009].

In view of the fact that multiple-partner matings by females occur in so many primate species [Dixson, 2012], we should expect sperm competition and cryptic female choice to have significantly impacted the evolution of primate reproduction. Moreover, in practice, the 2 processes are often closely entwined (Fig. 1). In what follows, I shall review the current knowledge of copulatory and postcopulatory sexual selection in the prosimians, monkeys and apes. Where appropriate, the results of research on other mammals must also be considered. Finally, I shall discuss how comparative studies can help us to better understand human reproduction and its evolution.

\section{Sperm Competition}

\section{Multiple-Partner Matings by Female Primates}

The potential for copulatory, or postcopulatory, sexual selection to occur in any given species is strongly influenced by its mating system. When attempting to define primate mating systems, 2 important considerations arise: first, does a female usually mate with just 1 male or with multiple partners during her fertile period and, second, are her sexual relationships long-term and relatively exclusive or short-term and non-exclusive? This line of reasoning results in the recognition of the 5 mating systems: monogamy, polygyny, polyandry, multimale-multifemale, and dispersed [Dixson, 1997, 2012]. In monogamous, polygynous and polyandrous primate groups, females have longer-term sexual relationships either with a single male or, in the (rare) case of polyandry, with 2 or more partners. In multimale-multifemale and dispersed systems, by contrast, females mate with a number of males in a more labile, non-exclusive manner. Indeed, in both these last 2 systems males as well as females engage in multiple-partner matings; for this reason such systems are sometimes referred to as being "polygynandrous."

When using this classification scheme, it is necessary to acknowledge that more than 1 mating system sometimes occurs within a single species, e.g., monogamy and polyandry in some marmosets and tamarins, or monogamy, polygyny and (rarely) polyandry in human beings. However, it is usually the case that each species has a clearly identifiable primary mating system, whereas others are of secondary importance [Dixson, 1997, 2012]. One must also recognize that social group composition does not always correspond to a species mating system. DNA typing studies have 
Fig. 1. Schematic representation of sperm competition and cryptic female choice. As well as competition between the gametes of rival males for access to a given set of ova, the female's anatomy and physiology may exert cryptic effects upon the fates of spermatozoa from different males [Dixson, 2009].

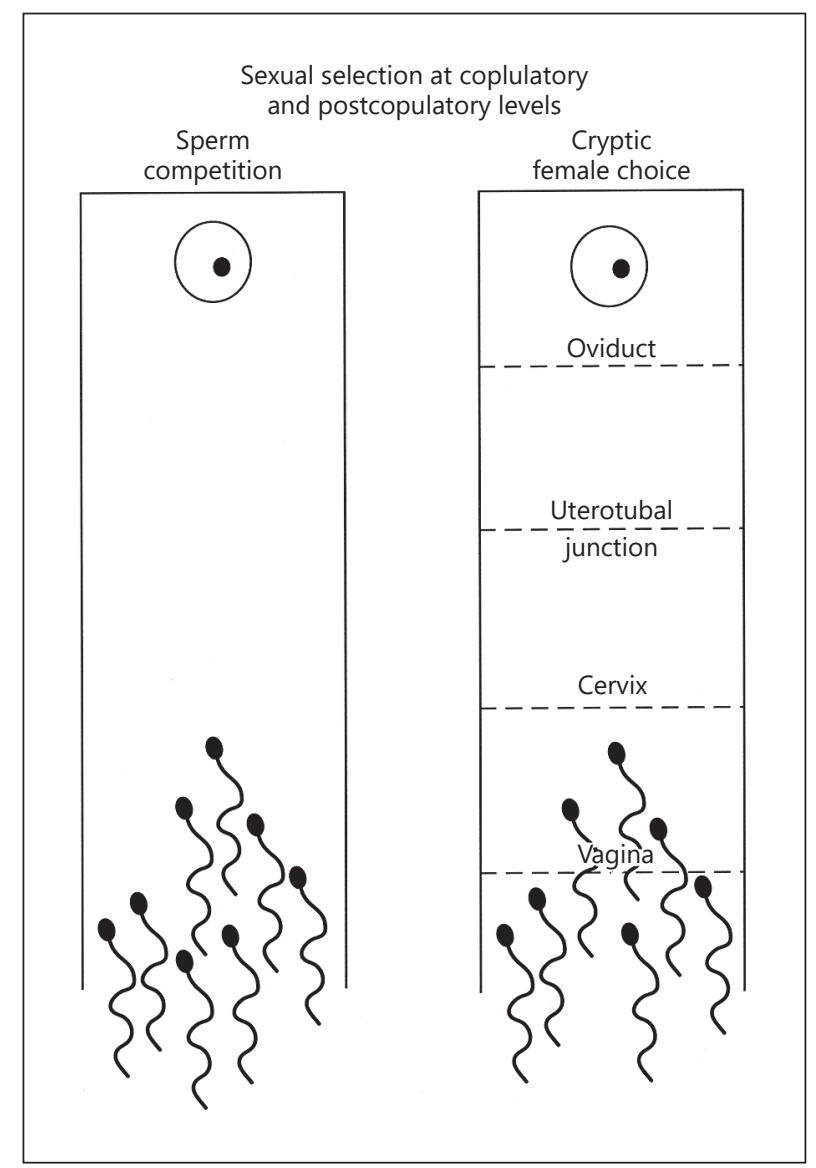

shown that some ostensibly pair-living primates are not strictly monogamous, as they may exhibit high levels of extrapair paternity. This is the case in certain prosimians (e.g., Cheirogaleus medius [Fietz et al., 2000]; Phaner furcifer [Schülke et al., 2004]). Yet, in other cases, genetic studies have confirmed the existence of monogamous sexual relationships (e.g., in 10 out of 11 groups of Tarsius lariang [Driller et al., 2009]; in all the groups of Aotus azarai sampled by Huck et al. [2014] and in 92.7\% of 41 offspring in family groups of Hylobates lar [Barelli et al., 2013]). The same appears to be true of polygynous species so far studied (e.g., in Gorilla beringei: dominant silverbacks sire $85 \%$ of infants [Bradley et al., 2005]; in Alouatta seniculus: resident males in single-male groups sire all offspring [Pope, 1990]).

The available DNA evidence indicates that although sexual relationships in monogamous and polygynous mating systems are not always exclusive, the probability that multipartner matings and sperm competition will occur is much lower than in primates that have multimale-multifemale or dispersed mating systems. In these multiple-partner polygynandrous systems, sperm competition has greatly affected the evolution of the male genitalia. The evidence for this is discussed below. 


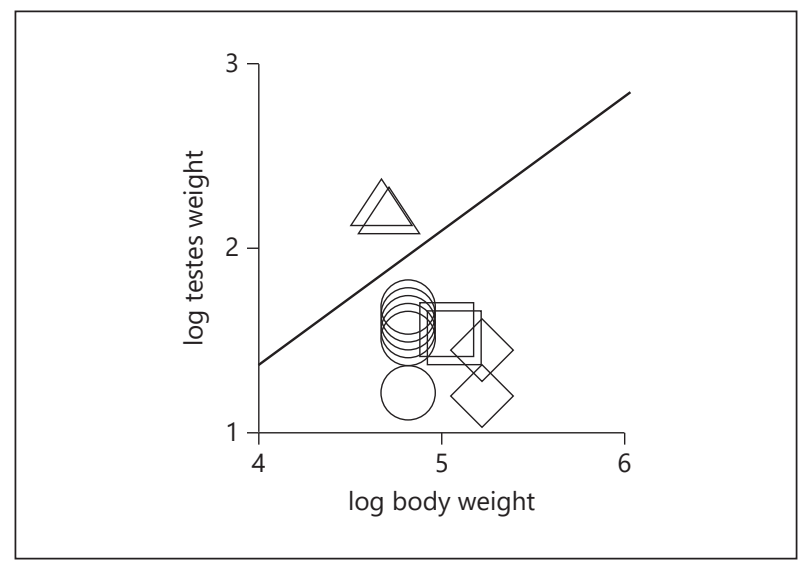

Fig. 2. Relative testes sizes in the great apes and in human populations worldwide (relative to body weight, in grammes). $\bigcirc=$ Homo; $\diamond=$ Gorilla (the western lowland gorilla is plotted separately and falls below the mountain gorilla on the graph); $\square=$ Pongo (Sumatran and Bornean species are shown separately); $\triangle=\operatorname{Pan}$ (data on the bonobo and chimpanzee are plotted separately). Data for 14 human populations are included, but in some cases points fall directly on top of each other, and cannot be distinguished individually. Smallest are the testes of Hong Kong Chinese, whereas the largest testes sizes are for men in Nigeria [Dixson, 2009].

\section{Relative Testes Sizes and Mating Systems}

Sperm competition, mating rate and sperm limitation have affected the evolution of expenditure on testes in primates, as in many other groups of animals [Parker, 2016]. Short [1979] and Harcourt et al. [1981] were the first to apply Parker's [1970] original insights concerning sperm competition to studies of primate reproduction. Harcourt et al. examined relationships between relative testes sizes and mating systems in 33 species of monkeys and apes, as well as human beings. Species with multimale-multifemale mating systems, such as macaques, baboons and chimpanzees, were shown to have larger testes (in relation to their body weights) than polygynous species (e.g., proboscis monkeys, geladas and gorillas) or those that have monogamous mating systems (e.g., owl monkeys and gibbons). This indicated that sexual selection, via sperm competition, selects for larger testes, and hence for greater investment in sperm production, in those primates that are polygynandrous. Subsequently, it became apparent that testicular physiology may also adjust to differences in social rank, so that in certain cases subordinate males have smaller testes, in relation to their body weights, than dominant males (e.g., Mandrillus sphinx [Wickings and Dixson, 1992]; Galago moholi [Pullen et al., 2000]; Propithecus verreauxi [Lewis, 2009]).

Data on 4 men were also included in the study of Harcourt et al. [1981], and these indicated that human testes are relatively small for body size. Figure 2 presents the results of a more recent analysis that includes data for more than 7,000 men, representing 14 populations worldwide, as well as for all the great apes [Dixson, 2009]. This study showed that testes sizes vary significantly between human populations and are, in general, smaller in Asiatic men than in men of African and European descent. Despite these variations, all men have distinctly smaller testes than chimpanzees. These 
results confirm that the testes are relatively small in human beings and do not provide evidence for effects of sperm competition during human evolution.

Studies of relative testes size have also been carried out on prosimians, a number of species of which have dispersed (polygynandrous) mating systems and large testes [Dixson 1987, 1995a; Kappeler, 1997]. In many nocturnal genera (e.g., Galago, Otolemur, Galagoides, Perodicticus, Microcebus, Mirza, Nycticebus and Loris) adults occupy individual home ranges. Male ranges tend to be larger and to overlap those of neighbouring females. Males compete for access to receptive females and multipartner matings have been observed during fieldwork on a number of species (e.g., $G$. moholi [Pullen et al., 2000]; Microcebus murinus [Eberle and Kappeler 2004]; Loris lydekkerianus [Nekaris, 2003]).

Findings concerning relative testes sizes and sperm competition in primates have been confirmed by studies of a number of mammalian taxa (including marsupials, monotremes, bats, rodents and cetaceans). Larger testes are adaptive under conditions where females mate with multiple partners during their fertile periods, because they usually contain a greater volume of seminiferous tissue. Thus, males are capable of producing and storing larger numbers of spermatozoa prior to mating, and sperm counts in the ejaculate are greater [Møller, 1988, 1989]. There is also evidence that ejaculatory frequencies are significantly higher in those primate species that have multimale-multifemale mating systems than in polygynous and monogamous species [Dixson, 1995b].

\section{Sperm Production, Storage and Morphological Diversity}

The possibility that sexual selection might influence spermatogenesis and sperm production rates in mammals has been addressed by Ramm and Stockley [2010], who reported results of a comparative study of seminiferous epithelium cycle lengths in 50 species, belonging to 9 orders of mammals (including 11 primate species). They found that sperm competition selects for a shorter seminiferous epithelium cycle length and, hence, for faster rates of spermatogenesis. By contrast, larger mammals, and those that have longer sperm, tend to have longer seminiferous epithelium cycle lengths. Ramm and Stockley [2010] pointed out that some relationship might exist between selection for sperm length, sperm production rates and testicular architecture. The question of how sperm length might relate to seminiferous tubule diameter has been investigated in birds, by Lüpold et al. [2009]. They found that a marked positive correlation exists between sperm length and seminiferous tubule diameter in the New World blackbirds (Icteridae). Lüpold et al. concluded that "in vertebrates, in which spermatogenesis occurs radially within the seminiferous tubules, longer sperm require wider tubules." However, whether this finding might be applicable to the primates, or to mammals in general, has not been determined.

Has sexual selection influenced the evolution of sperm length in primates and other mammals? Gomendio and Roldan [1991] reported that longer sperm occurred in those species of primates and rodents where the sperm competition risk was greatest (due to multiple-partner matings by females). If sperm competition has influenced the evolution of longer gametes, one might expect to find a correlation between relative testes size and sperm length. However, comparative work on a wide range of mammals has failed to establish such a correlation [Gage and Freckleton, 2003; Anderson et al., 2005]. Gomendio and Roldan [1991] also reported a positive correlation between sperm length and swimming velocity, in a small sample of mammals for 
which adequate data existed. The implication was that if longer sperm swim more rapidly, then they might gain an advantage in sperm competition. In their more recent examination of this question, Gomendio and Roldan [2008] reviewed the literature and concluded that "sperm competition does seem to favour an increase in sperm size in a wide range of [vertebrate and invertebrate] taxa, but the adaptive significance of such changes may vary between taxa." They presented fresh evidence showing that increases in sperm length are associated with greater swimming velocity in mammals, and that "sperm swimming velocity is an important determinant of fertility."

Holt et al. [2010] conducted in vitro experiments to measure possible effects of sperm length upon sperm transport using glass columns and a "swim-up" technique. For all 3 mammals tested (brown hares, pigs and bulls), flagellar lengths were greater in the most successful sperm during these swim-up trials. Holt et al. [2010] also conducted an in vivo experiment, using pigs, to examine whether artificial insemination produced any differences in which sperm gained access to the uterotubal junction and isthmus of the oviduct. There were no effects of sperm length under these conditions, but statistical tests were not possible, as sperm were only attached to the epithelia of the uterotubal junction and isthmus of the oviduct in 2 out of 10 animals studied. Holt et al. noted that linear sperm swimming speeds depend upon the beat frequencies of their flagella, as well as upon flagellar length. It should not be assumed that slightly longer sperm are always the fastest or most successful gametes in an ejaculate.

The regular beating action of the sperm flagellum falls under the joint control of its component parts, the midpiece and the principal piece, but these operate via different regulatory systems [Suarez et al., 2007]. The sperm midpiece contains the mitochondria, which form a helical array, tightly wound around the central strut (axoneme) of the flagellum. Mitochondrial energy production by the midpiece involves oxidative phosphorylation to produce ATP, whereas in the sperm principal piece, energy for motility is generated by glycolysis [Cummins, 2010]. The extent to which these 2 processes govern sperm motility varies considerably among mammals [Bedford and Hoskins, 1990], and it remains unknown how far such variations might reflect phylogenetic factors or the effects of postcopulatory sexual selection.

One possible clue is that relative testes size is positively correlated with the volume of the sperm midpiece in primates [Anderson and Dixson, 2002] and among eutherian mammals in general ( $n=123$ species [Anderson et al., 2005]). The implication of these findings is that mammals with larger testes (and thus with a greater likelihood of engaging in sperm competition) tend to have larger sperm midpieces because mitochondrial loading and energy production are enhanced under these conditions. However, it must be acknowledged that correlations do not necessarily reflect the existence of causal relationships. Considerable scatter is apparent in plots of sperm midpiece size against relative testes size [Anderson et al., 2005]; thus, it appears that other factors independently influence these 2 variables.

Given the importance of glycolysis for sperm motility in some mammals (e.g., in equids, in the domestic boar and the mouse [Bedford and Hoskins, 1990; Cummins, 2010], much more research will be necessary to determine whether sexual selection has influenced mitochondrial function in the sperm midpiece. Where the primates are concerned, a study of mitochondrial activity in the sperm of chimpanzees and men has produced some useful insights [Anderson et al., 2007]. Living sperm from 4 


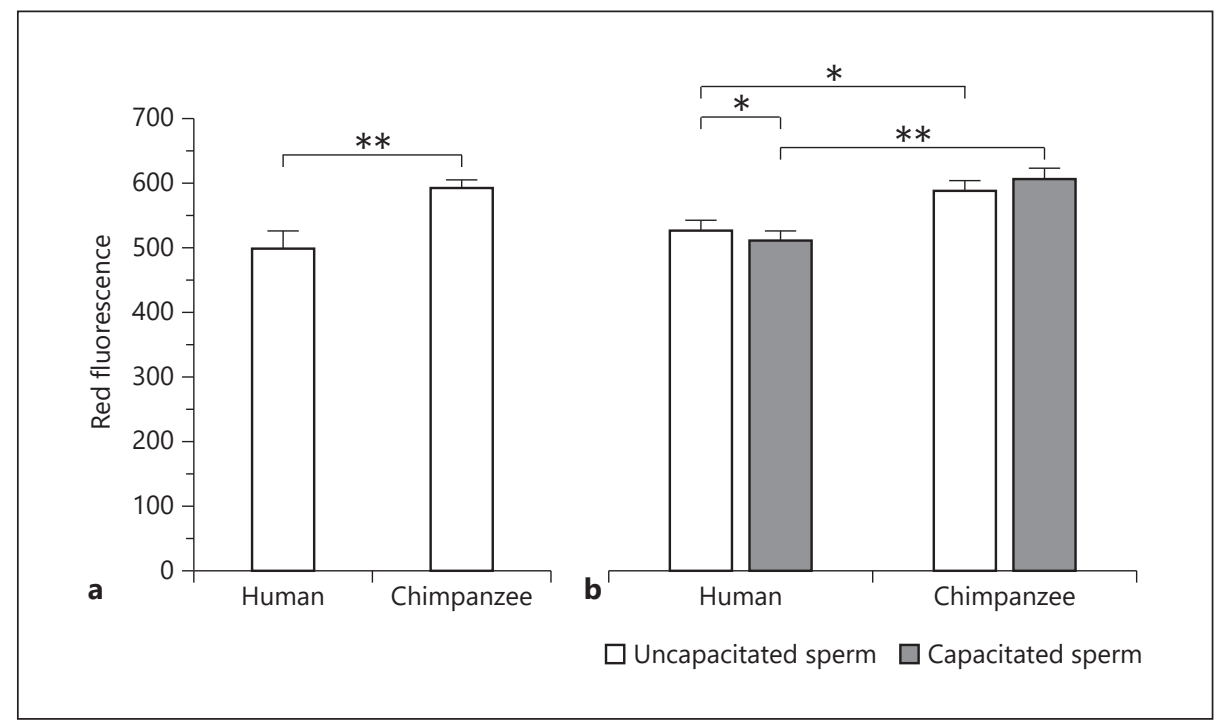

Fig. 3. a Red fluorescence values for JC-1-stained sperm samples from men and chimpanzees, as measured using flow cytometry. $\mathbf{b}$ Effects of in vitro induction of capacitation upon JC-1 staining (red fluorescence) of human and chimpanzee sperm. ${ }^{*} p<0.05$; ${ }^{* *} p<0.01$ [Dixson, 2009; after Anderson et al., 2007].

men and 5 chimpanzees were treated with JC-1, a fluorescent dye that stains metabolically active mitochondria red/orange. Intensity of staining provides a measure of mitochondrial membrane potential. Results showed that fluorescence intensities were markedly higher in the sperm of the chimpanzee (Fig. 3). These differences persisted when chimpanzee and human sperm had undergone (in vitro) capacitation, a process which normally takes place in the female reproductive tract and which prepares sperm physiologically to fertilize ova. Whereas JC-1 staining tended to decrease after capacitation in human sperm, this was not the case in chimpanzees (Fig. 3). Capacitated sperm are capable of exhibiting vigorous hyperactivated motility, which normally occurs as sperm ascend the oviduct prior to fertilization [Yanagimachi, 1994]. These JC-1 studies strengthen the conclusion that differences in sperm midpiece volumes in primates may indeed relate to differences in mitochondrial loading and sperm bioenergetics. There is also evidence from comparative studies of human and rhesus macaque sperm [Zhou et al., 2015] that genetic and ultrastructural differences between their sperm midpieces are consistent with observed differences in sperm motility and sperm competition between the 2 species.

\section{Altruistic Sperm?}

As Robert Trivers [1985] has pointed out, "if close degrees of relatedness predispose individuals to altruism, why not search for such examples in sex cells, specifically sperm?" Postcopulatory sexual selection might thus be expected to encourage the evolution of cooperation between the gametes produced by individual males in order to secure some advantage during sperm competition. Among mammals, only 
Fig. 4. Seminal vesicle sizes and seminal coagulation ratings for primate genera in which females mate primarily with single partners, or with multiple partners, during the fertile period. Data (means + SEM) are ratings on a 4-point scale for seminal vesicle size (where $1=$ vestigial and $4=$ large) and seminal coagulation (where 1 = no coagulation and $4=$ copulatory plug formation). *** $p<0.002$ [Dixson, 1998; Dixson and Anderson, 2002].

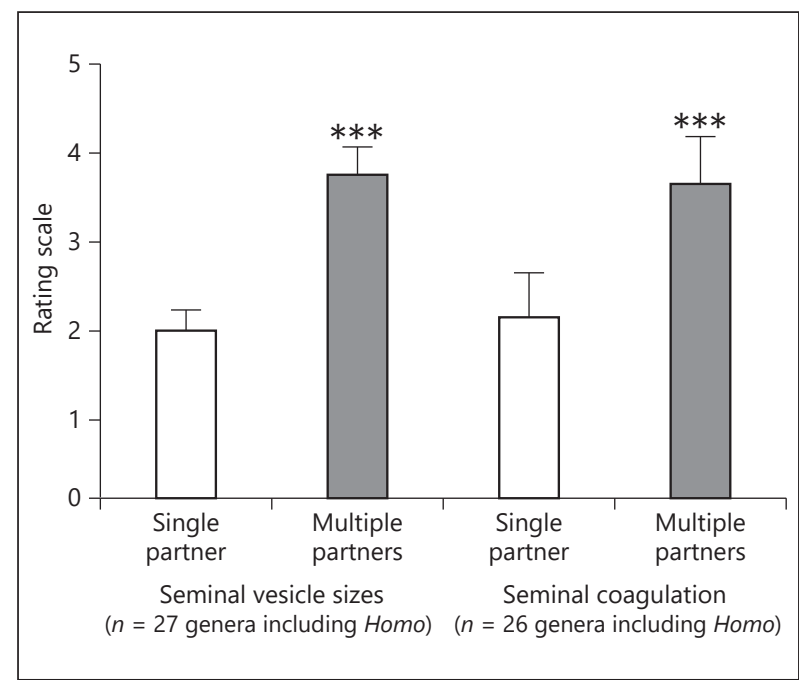

a few such cooperative adaptations have been documented and there is some evidence that they enhance sperm motility. Examples include the binary sperm of many South American marsupials [Taggart et al., 1993], the sperm bundles of the echidna and platypus [Grützner et al., 2008] and the hooked acrosomes of some rodent taxa, which may assist sperm to link together and move in cohorts [Moore et al., 2002].

\section{The Male Accessory Reproductive Glands and Ducts}

The accessory reproductive glands, and principally the prostate gland and seminal vesicles, secrete the major fluid component of the semen, in which spermatozoa are suspended at ejaculation. The primates, in common with all eutherian and metatherian mammals, possess a prostate gland, but seminal vesicles are absent in marsupials, whilst among eutherians they vary tremendously in size or are lacking in some cases. There is now considerable evidence that these variations result, in part, from postcopulatory sexual selection [Dixson, 1998; Dixson and Anderson, 2002; Anderson and Dixson, 2009]. Thus, in primates that have polygynandrous mating systems, such as macaques, most baboons, mandrills and chimpanzees, the seminal vesicles are very large, whereas in monogamous and polygynous taxa (e.g., in geladas, gorillas and gibbons) they are significantly smaller (Fig. 4).

In some monogamous New World monkeys (e.g., Pithecia pithecia and Callicebus torquatus) only vestiges of the seminal vesicles remain. Given that the vesicles are energetically expensive organs, producing secretions rich in proteins, fructose and other constituents, it is probable that natural selection has favoured reduction in their bulk under conditions where copulation occurs less frequently and the need for a larger ejaculate volume is reduced. Indeed, ejaculatory frequencies are significantly lower in monogamous/polygynous primate genera than in those that have multimale-multifemale mating systems [Dixson, 1995b].

Comparative studies of rodents, and a variety of other mammals including primates, have confirmed that taxa which exhibit large relative testes sizes also have the 
largest prostate glands and seminal vesicles in relation to their body weights [Ramm et al., 2005; Anderson and Dixson, 2009]. One important chemical secreted by the prostate gland is vesiculase, an enzyme which mixes with proteins (semenogelins) produced by the seminal vesicles to cause semen to coagulate once ejaculation has occurred. The cranial lobe of the prostate plays a crucial role in this process; its removal (in the rhesus monkey) prevents the coagulation of semen [Greer et al., 1968]. None of the primates for which adequate information exists exhibits complete absence of coagulation. However, in some taxa, and especially in those that have polygynandrous mating systems, coagulation is more pronounced and results in the production of a substantial coagulum or a copulatory plug. For example, mouse lemurs, ring-tailed lemurs, lorises, black-handed spider monkeys, muriquis and chimpanzees all produce copulatory plugs, and all of these species have polygynandrous mating systems [Dixson and Anderson, 2002]. Hernández-López et al. [2008] have shown that, in black-handed spider monkeys (Ateles geoffroyi), the copulatory plug promotes the passage of highly motile, linearly moving sperm through the cervix. The plug also serves to buffer $\mathrm{pH}$ and to raise the temperature of the vagina. These effects, which improve sperm survival in the vagina and transcervical transport, are important in the context of multiple-partner matings by females and resultant sperm competition between rival males. At the present time such findings provide the most likely explanation for the evolution of pronounced seminal coagulation and plug formation in many polygynandrous primate species (Fig. 4). An alternative, but not mutually exclusive hypothesis is that a copulatory plug might obstruct semen deposition and sperm transport by a second male. For further discussion of these questions, see Dixson [2012].

Genetic studies of the primate semenogelins have strengthened the conclusion that copulatory and postcopulatory sexual selection has influenced the functions of the seminal vesicles [Jensen-Seaman and Li, 2003; Dorus et al., 2004]. Rates of evolution of the semenogelin 2 gene have progressed more rapidly in species that exhibit large relative testes sizes and marked semen coagulation. By contrast, the rate of semenogelin 2 gene evolution in Homo sapiens is comparable to that of other monogamous, or polygynous, primates and notably less rapid than that which occurs in polygynandrous species such as the chimpanzee [Dorus et al., 2004]. Recently, Hergenrother [2015] has found that the evolution of prostate-specific gene expression indicates that the last common ancestor of humans and chimpanzees was not polygynandrous. Specializations for sperm competition in chimpanzees and bonobos most likely arose after the lineage which gave rise to Pan had separated from that which gave rise to the genus Homo. Indeed, although many authors have equated the common ancestor of chimpanzees and humans as being similar to the modern chimpanzee, this is misleading, especially where various features of its reproductive anatomy and sexual behaviour are concerned [Dixson, 2009].

The rapid transport of many millions of spermatozoa within the male reproductive tract during copulation is a complex process. Beyond the cauda epididymis, where sperm are pooled and stored, lies the vas deferens. During mating, sperm are transported rapidly through the vas by peristaltic contractions of its muscular walls. Typically, 3 layers of smooth muscles are present; there are 2 sets of longitudinal muscles which are separated by a layer of circular muscles. These muscles surround a narrow central lumen. 


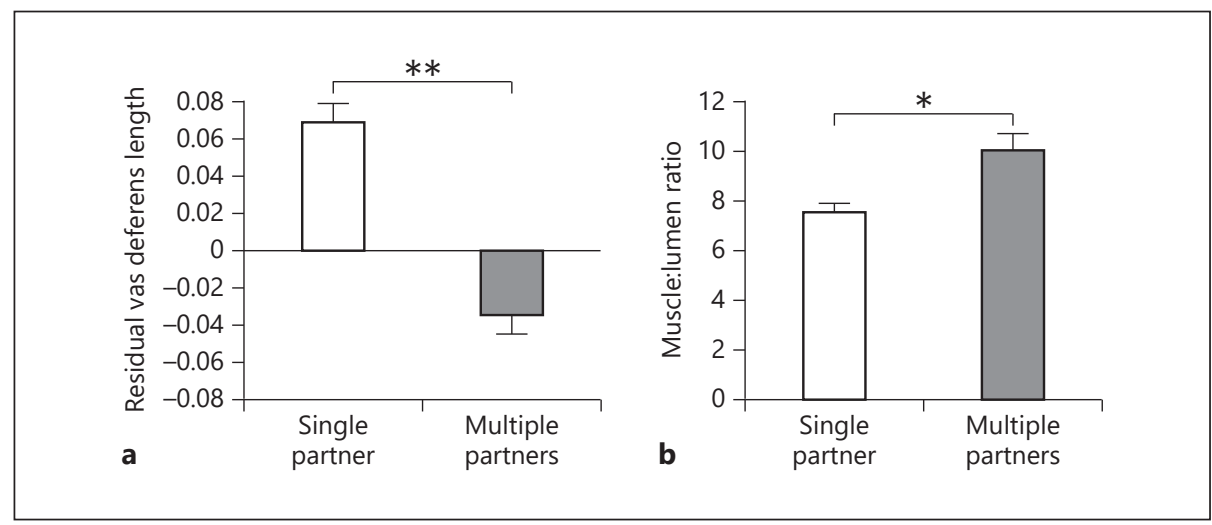

Fig. 5. Vas deferens length (a) and thickness (muscle wall:lumen ratio, b) in mammals where females have single-partner versus multiple-partner mating systems. ${ }^{*} p<0.05,{ }^{* *} p<0.01$ [Dixson, 2009; redrawn from Anderson et al., 2004].

In mammals, the vas deferens is significantly shorter and the combined thickness of its muscle layers is greater in species where females mate with multiple males, rather than with a single partner (Fig. 5). The outer and inner layers of longitudinal muscles, in particular, are thickest in mammals that have multiple-partner mating systems [Anderson et al., 2004]. These specializations are consistent with effects of sexual selection acting at the copulatory level, to maximize the efficiency of sperm delivery in species that engage in sperm competition.

In some primates that have multimale-multifemale mating systems (e.g., many macaques and baboons) males make a series of intromissions, with pelvic thrusting, to attain ejaculation. In the rhesus macaque, for example, more than 1,000 million sperm are transferred to the female during the final mount of the series. It is possible that sperm are moved along the vas deferens in cohorts during each mount so that numbers are maximized prior to ejaculation, but this hypothesis has yet to be tested. Nor do we know whether the vas might serve to transport sperm in the reverse direction, so as to replenish the cauda epididymis if a male ceases to complete a series of mounts. Such interruptions are by no means unusual, e.g., in Japanese macaques [Hanby et al., 1971]. Reverse transport of sperm, returning them to the cauda epididymis, occurs in buck rabbits [Prins and Zaneveld, 1980]. However, to my knowledge, this possibility has not been investigated in primates.

\section{Sexual Selection and Penile Morphology}

Comparative studies of many invertebrate taxa led William Eberhard [1985, 1996 ] to propose that in species where females mate with multiple partners, rather than with a single male, sexual selection has favoured the evolution of complex penile morphologies. He posited that the penis functions as an "internal courtship device," stimulating responses in the female partner that facilitate successful sperm transport, or storage, within her reproductive tract. Any male that has a more effective penile 


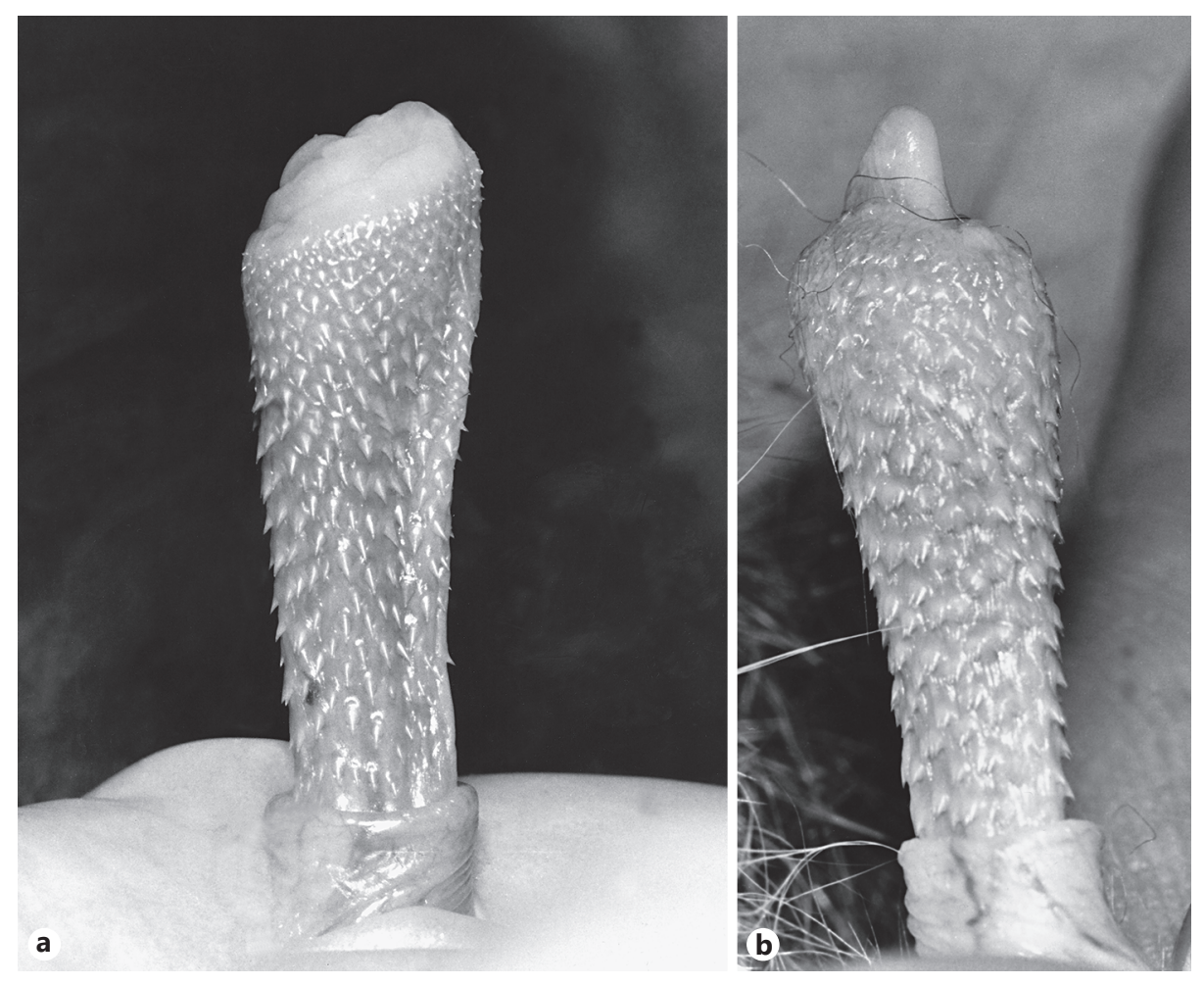

Fig. 6. Differences in penile morphology between 2 closely related species of the greater galago. a Otolemur crassicaudatus. The glans penis is covered in robust type spines. The baculum projects slightly beyond the tip of the glans. b Otolemur garnettii. The glans penis is covered in complex multipointed spines. The baculum projects much further beyond the tip of the glans. Author's photographs.

morphology and/or copulatory pattern will therefore gain a reproductive advantage over rival males. This is the basis of the concept of cryptic female choice, and, as stated in the Introduction, it is probable that both cryptic choice and sperm competition have sometimes evolved in concert to influence sexual selection at copulatory as well as postcopulatory levels.

\section{Phallic Diversity and Primate Mating Systems}

The first attempt to apply Eberhard's hypothesis to a vertebrate taxon involved a quantitative study of the penile morphologies and mating systems of 130 primate species [Dixson, 1987]. Results of this initial attempt showed that primates having polygynandrous (multimale-multifemale and dispersed) mating systems had significantly more complex penile morphologies than monogamous and polygynous species. Specialized traits included a more complex distal penile shape, a longer baculum (os penis), larger penile spines, and a greater penile length among the polygynandrous taxa. The most problematic finding concerned the penile spines. Large spines are far more common and 


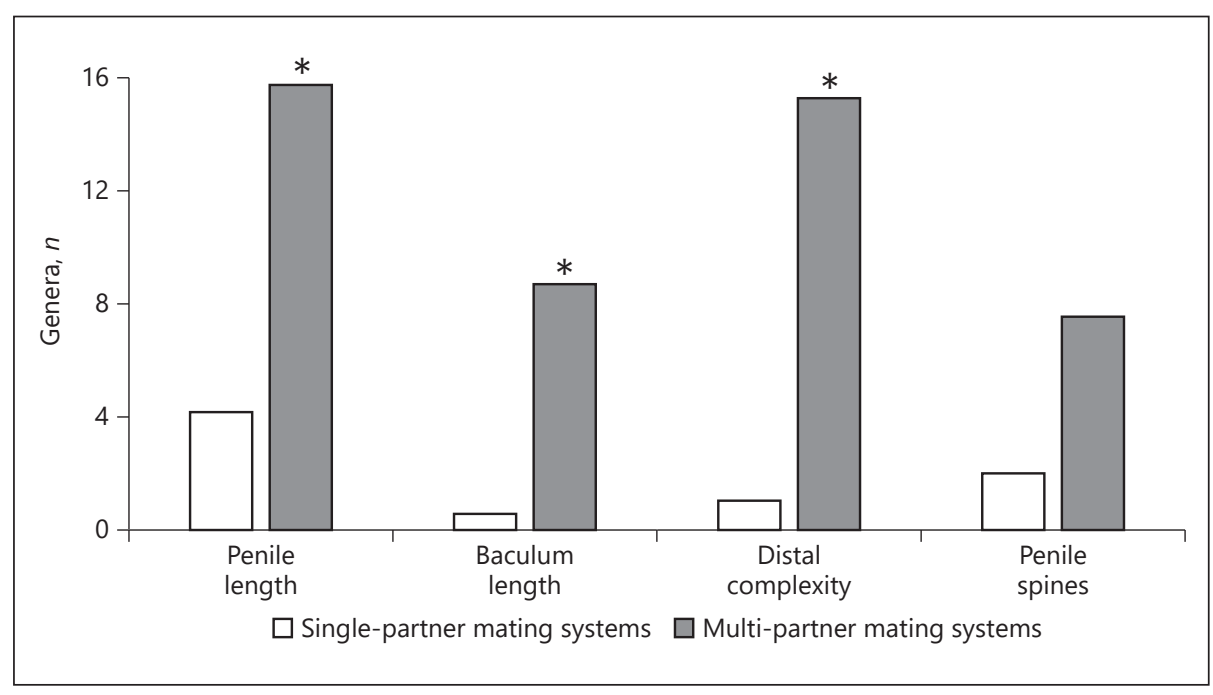

Fig. 7. Penile morphologies are more complex in primate genera where females mate with multiple males than in genera where single partners are the norm. Data are for 48 genera (including Homo) and show the numbers of genera which received the highest ratings (4 or 5 on a 5-point scale) for various phallic traits. ${ }^{*} p<0.05$ [Dixson, 2009].

more morphologically variable among prosimians than among the anthropoid primates (see Fig. 6 for an example of this in the genus Otolemur). That a lack of any statistical control for phylogeny had biased the results was shown by Harcourt and Gardiner [1994]. However, a subsequent study of primate penile spines [Stockley, 2002], reported that "after control for phylogenetic effects relatively high penile spinosity is associated with a relatively short duration of female receptivity within the ovarian cycle." The diverse functions of primate spines will be discussed in greater detail below.

A more recent examination of possible correlations between penile complexity and mating systems in primates [Dixson, 2009] was able to draw upon up-to-date information for 48 genera, including the genus Homo. The results (Fig. 7) provide some useful comparisons as far as H. sapiens is concerned. Numerous authors have stated that the human penis is exceptionally large and specialized when compared to other primates. Indeed, at least 11 books published between 1982 and 2010 include such statements [Dixson, 2012]. In reality, apart from its girth, the human penis is not unusual, and even that trait is far from unique. The overall rating score for all 4 penile traits considered in Figure 7 is 10 for H. sapiens. This is the same score as that assigned to monogamous and polygynous monkeys such as Callimico, Leontopithecus, Erythrocebus and Theropithecus. Humans have lower overall scores for penile complexity than 27 of the 48 genera considered. Our species does achieve a maximum score for 1 trait (penile length). However, 16 non-human primate genera also have maximum ratings for this trait, and 21 genera have higher ratings for distal complexity (e.g., shape and size of the glans penis). These results do not support the hypothesis that sexual selection has influenced the evolution of human penile morphology [e.g., Smith, 1984; Baker and Bellis, 1995; Gallup et al., 2003]. 
Fig. 8. Penis of Brachyteles (the muriqui or woolly spider monkey) to show the internal structures and arrangement of the baculum. BA, baculum; $\mathrm{CC}$, corpus cavernosum; CS, corpus spongiosum; GL, glans; TA, tunica albuginea. The scale is in 1-cm divisions [Dixson et al., 2004b].

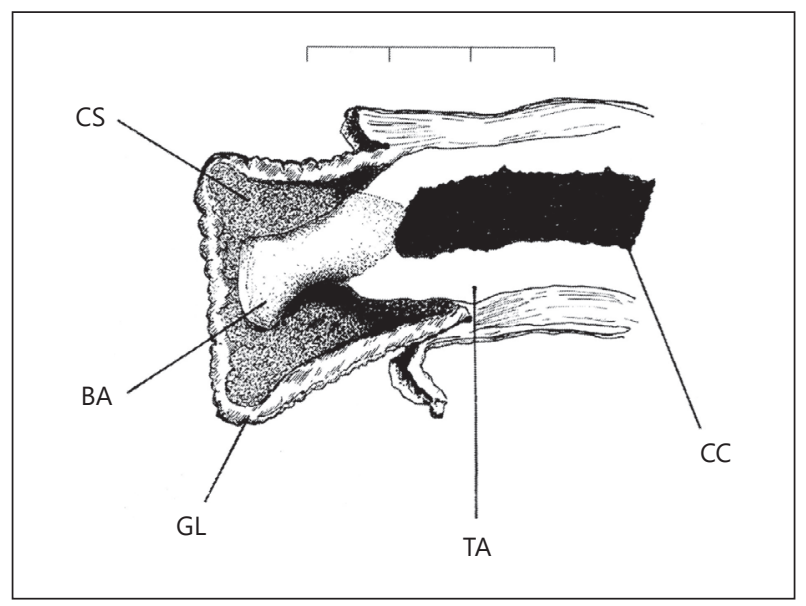

\section{Sexual Selection and the Baculum}

The baculum or os penis is a primitive (plesiomorphic) trait for the order Primates. Thus, it is present in most prosimian and anthropoid species but has undergone secondary reduction, or loss, in a number of cases (e.g., in Ateles, Chiropotes, Cacajao, Tarsius and Homo [Dixson, 2012]). Bacula also occur in some species belonging to the following orders of placental mammals: Chiroptera, Rodentia, Eulipotyphla, Lagomorpha, Carnivora, Pinnipedia and Afrosoricida [Brindle and Opie, 2016; Schultz et al., 2016]. The baculum forms by ossification of the distal region of the corpora cavernosa and extends forwards into the glans penis (Fig. 8). Growth of the penis during puberty is accompanied by enlargement of the baculum and is stimulated by testosterone. Indeed, the baculum may have arisen during evolution because it provides additional support to the distal end of the penis during erection, and thus assists the male to gain intromission. This is the case in the rat, for example, where it serves to strengthen the more labile glans penis before and during intromission [Kelly, 2000].

The baculum has become greatly elongated in some primates and in other mammals; the possible reasons for this have been much debated. In a thick-tailed galago (Otolemur crassicaudatus), weighing $1.5 \mathrm{~kg}$, the baculum is about $22 \mathrm{~mm}$ long, similar to that of a male yellow baboon (Papio cynocephalus) that is more than $20 \mathrm{~kg}$ in weight. An adult male gorilla has a diminutive baculum $(12.6 \mathrm{~mm})$ despite its enormous size, whereas in the stump-tailed macaque (Macaca arctoides) the bone is 51 $\mathrm{mm}$ in length. Body size and phylogenetic factors alone cannot account for these differences. More importantly, there is a marked correlation between elongation of the baculum and copulatory patterns that involve prolonged intromission and maintenance of intromission once ejaculation has occurred [Dixson, 1987, 2012; Dixson et al., 2004a]. Both the thick-tailed galago and the stump-tailed macaque, for example, exhibit this type of copulatory behaviour; hence they have very long bacula in relation to body size. Primate species that engage in lengthy copulations have polygynandrous mating systems and large relative testes sizes. Hence elongation of the baculum forms part of a suite of specializations for sperm competition/cryptic female choice. Please 
Fig. 9. Relationship between baculum length, corrected for body weight, and the duration of intromission in 54 species of primates, carnivores and pinnipeds. Spearman rank correlation coefficient $r_{\mathrm{s}}=0.746 ; p<0.001$. Based upon data in Dixson et al. [2004a].

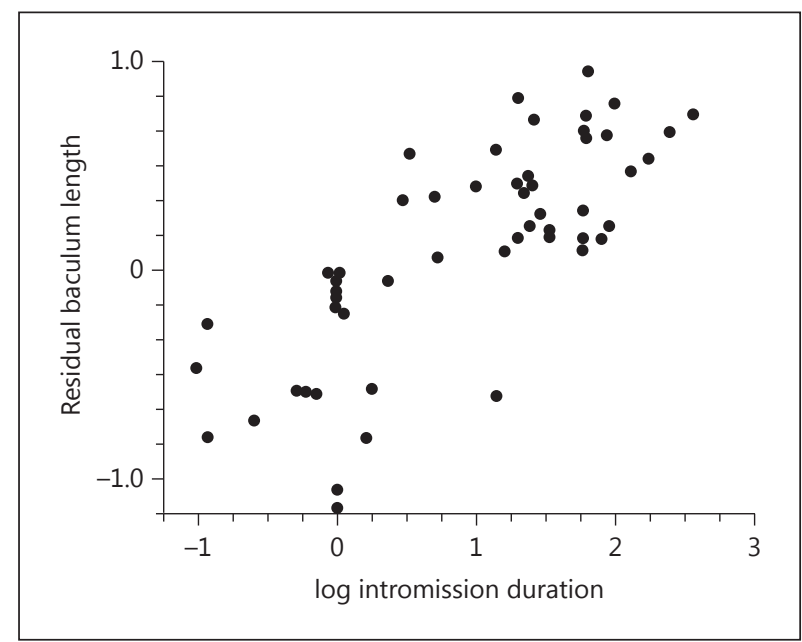

note, however, that not all primates that exhibit prolonged copulations necessarily have a baculum (e.g., spider monkeys lack this trait [Dixson, 2012]).

A significant correlation exists between baculum length (relative to body weight) and intromission duration in primates, carnivores and pinnipeds (Fig. 9). Elongation of the baculum might fulfil a number of functions during mating, depending upon the species concerned. Considerable pressure may be placed upon the urethra during extended matings (e.g., 15-30 min: red fox; 24 min: Canadian otter; 1-2 h: weasels and martens; 2 h: Otolemur garnettii [Dixson et al., 2004b]). An elongated baculum might serve to protect the urethra under these conditions. It is also possible that extended copulations by males may function as a type of mate-guarding strategy; this may be particularly advantageous in some of the prosimians where the duration of sexual receptivity is short, and copulation itself may shorten the receptive period [Dixson, 2012]. It is unlikely, however, that the baculum plays any role in inducing ovulation, at least among the primates, given that all primate species studied thus far are spontaneous ovulators.

In the stump-tailed macaque, the large baculum helps to support the elongated glans penis during copulation. The male deposits a remarkable, crescent-shaped copulatory plug and maintains intromission during a "postejaculatory pair-sit" [Dixson, 2012]. This behaviour, coupled with the male's unusual penile morphology, may help to position the plug within the female's enlarged ectocervix. In some primate species the distal pole of the baculum extends beyond the tip of the glans penis, with the opening of the urinary meatus on its ventral surface (Fig. 6). This arrangement, coupled with the fact that the penis is very long in these animals, may bring its tip into contact with the os cervix during intromission, and thus facilitate semen transfer directly into the cervical canal. Such an arrangement might be viewed as benefitting males via sperm competition, or cryptic female choice, as the cervix constitutes an initial barrier to sperm as they begin to negotiate the female's reproductive tract.

An effect of sexual selection upon the evolution of the baculum has been demonstrated experimentally in mice [Stockley et al., 2013; Simmons and Firman, 2014]. 
In the study by Simmons and Firman, 8 populations of mice were bred across 27 generations. Four populations reproduced under conditions where females mated with multiple partners ( 3 males in close succession), and 4 populations reproduced under conditions of enforced monogamy. The bacula of males were significantly thicker (but not longer) in the 4 populations where females mated with multiple partners, indicating possible effects of copulatory/postcopulatory sexual selection upon bacular morphology. Mice do not exhibit long intromissions; their mating pattern involves a series of brief intromissions, culminating in ejaculation. This copulatory pattern stimulates neuroendocrine responses in female mice which are important for the support of the corpus luteum during early pregnancy [McGill and Coughlin, 1970]. Multiple intromissions could also serve to loosen or remove copulatory plugs deposited by rival males. Hence in this case, evolution of thicker bacula might result from either sperm competition, cryptic female choice or a combination of both processes.

\section{Sexual Selection and Penile Spines}

Penile spines are androgen dependent, keratinized structures that occur on the surface of the glans penis (and adjacent areas) in many primates, and in some other eutherians (e.g., rodents, carnivores and bats), as well as in some marsupials and in the duck-billed platypus [Dixson, 2012; Orr and Brennan, 2016]. During human evolution, however, loss of an enhancer sequence situated close to the androgen receptor gene has resulted in the loss of penile spines [Reno et al., 2013]. This regulatory enhancer is an inferred ancestral mammalian feature. It occurs in the great apes and in other primates that have penile spines and facial vibrissae. However, the enhancer is missing in humans and also in Neanderthals and Denisovans.

Penile spines may be classified into 3 categories: type 1, single-pointed small structures; type 2, much larger, robust, single-pointed spines; type 3, large, complex, multipointed structures. Type 1 spines occur widely among prosimian and anthropoid taxa; they probably represent the least specialized morphology. Although type 2 spines may be found in a few monkey species (e.g., M. arctoides and Cacajao calvus), they occur much more frequently in prosimians (e.g., in Euoticus, Sciurocheirus, Ava$h i$ and Phaner). Type 3 complex spines occur exclusively among prosimians (e.g., in O. garnettii, Eulemur, Lemur and Microcebus). Examples of spine types 2 and 3 are shown in Figure 6.

In evolutionary terms, it is possible that small type 1 spines arose because they enhance penile sensory feedback during copulation. Beach and Levinson [1950] originally suggested that, in the rat, deflection of the penile spines during pelvic thrusting might enhance tactile signals required to achieve intromission and/or ejaculation. This hypothesis gains some support from work conducted on the common marmoset [Dixson, 1991]. Removal of the type 1 spines from the glans penis has subtle (but statistically significant) effects upon intromission latencies and intravaginal thrusting durations in male marmosets (Fig. 10).

The role that penile spines might play in copulatory and postcopulatory sexual selection is still largely a matter for conjecture. There are at least 4 possible lines of enquiry and these mainly concern the larger, type 2 and type 3, spines. It should be stressed that none of these is mutually exclusive.

1 Large spines may grip the walls of the vagina during prolonged copulations, that involve a "genital lock" or partial lock between the sexes (e.g., in Otolemur, Galagoides, Microcebus). For example, the large type 2 spines on the long glans penis of 


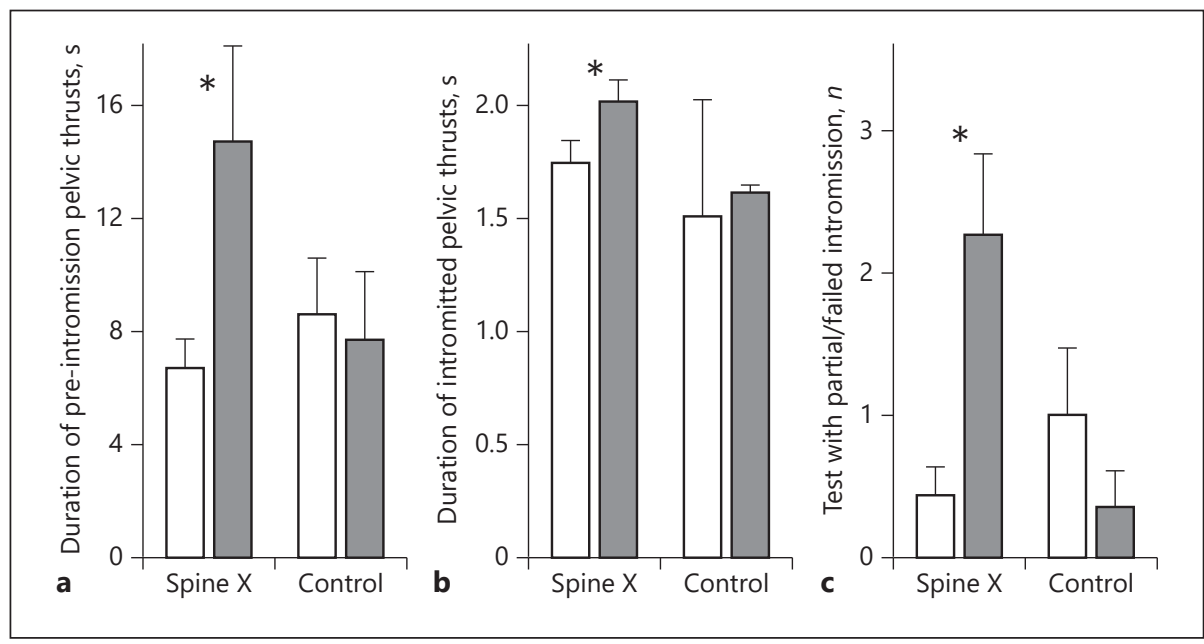

Fig. 10. Effects of penile spine removal (spine $X$ ) or a sham operation (control) upon copulatory behaviour (a-c) in male common marmosets (Callithrix jacchus). $\square$, pre-operative data; $\square$, postoperative data. $* 00.05$ [Dixson, 1991].

the Australian hopping mouse (Notomys alexis) are known to facilitate this type of genital lock [Breed, 1981; Dewsbury and Hodges, 1987].

2 Spines may impart tactile stimulation to the female and facilitate neuroendocrine responses affecting the duration of receptivity. In O. garnettii, for example, the duration of receptivity is shortened if prolonged copulations are allowed to run their full course, rather than partners being separated during laboratory "pair-tests." In Lemur catta copulations are quite brief, and females are receptive for approximately $24 \mathrm{~h}$ when pair-tested in the laboratory. However, in the wild, where females mate repeatedly with multiple partners, receptivity is reduced to $4 \mathrm{~h}$ on average [Koyama, 1988]. Whether this is due to copulatory stimulation involving the type 3 spines or to a postcopulatory effect of the large copulatory plugs produced by males of this species is not known.

3 Sexual selection by cryptic female choice may have encouraged the evolution of large spines which stimulate the receptive female and encourage her to remain immobile during copulation. This hypothesis is more applicable to prosimians than to the anthropoids, because female prosimians exhibit oestrus, and in some cases they adopt a lordotic posture during mating. In the rat, for example, penile stimulation of the vagina and cervix enhances the expression of lordosis [Rodriquez-Sierra et al., 1975].

4 Penile spines may assist in the removal of coagulated semen and plugs deposited by previous matings, and hence reduce potential sperm competition. Hershkovitz [1993] suggested such a role for the large type 2 spines of C. calvus. Parga [2003] reported incidences of plug displacement by male L. catta, which raises the question of whether the large penile spines might play a role in this process. Experimental studies to examine mechanisms of plug displacement in primates are lacking, however. 


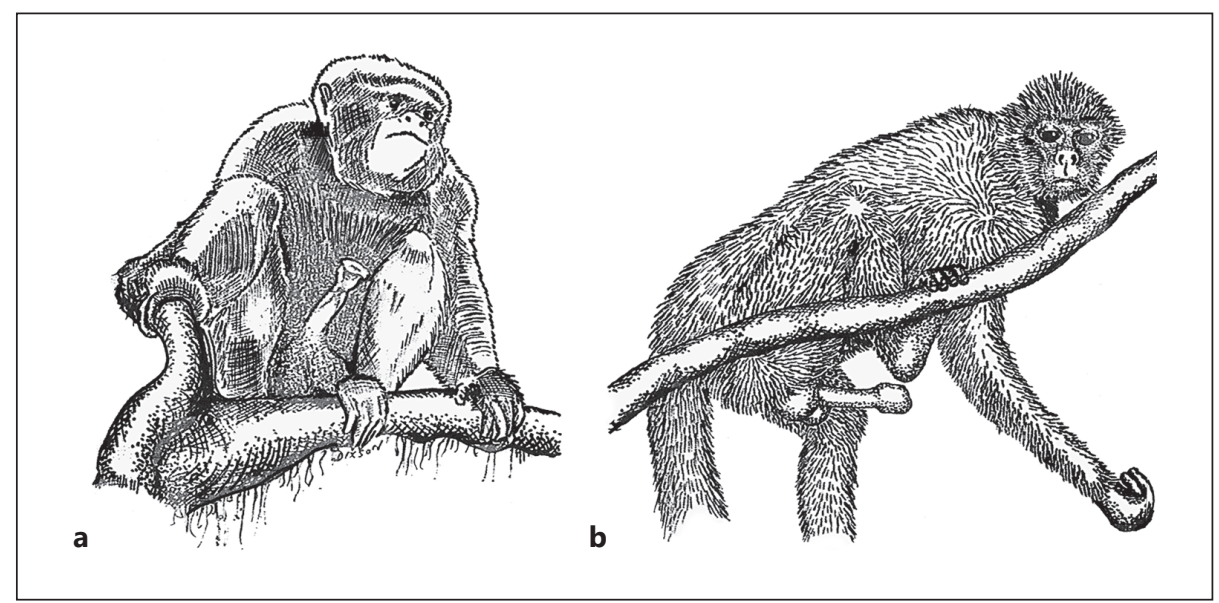

Fig. 11. a Male woolly monkey (Lagothrix lagotricha) showing the large size of the penis and plunger-shaped glans during full erection. Author's drawing, after Nishimura [1988]. b Spider monkey (Ateles geoffroyi) showing the mushroom-shaped glans of the erect penis [Campbell, 2007].

\section{Sexual Selection and the Striated Penile Muscles}

Muscles situated at the base of the penis are responsible for the expulsion of semen during ejaculation and for reflexive penile movements that accompany intromission or ejaculation. These events may be important in cryptic female choice, therefore, as they relate to the possible role of the penis as an "internal courtship device" [Eberhard, 1985, 1996]. Most important in the present context are the bulbocavernosus (sometimes called bulbospongiosus) muscles. In the rat, these muscles bring about a reflexive flaring or "cupping" of the glans penis during intromission. During non-ejaculatory intromissions this penile reflex serves to dislodge plugs deposited by previous males. Then, during the ejaculatory mount, the cupping reflex packs and seals the male's own copulatory plug against the female's cervix [Hart and Melese-d'Hospital, 1983; Sachs, 1983].

The bulbocavernosus muscles vary greatly in size among the primates and there is preliminary evidence that these differences are due in part to the effects of sexual selection. Thus, polygynandrous primates have significantly larger bulbocavernosus muscles than those that have monogamous or polygynous mating systems [Dixson, 2012]. As well as controlling ejaculation, contractions of these muscles, which surround the corpus spongiosum at the base of the penis, cause marked changes in the size and shape of the glans penis. The glans pulsates rapidly during ejaculation in some species (e.g., in Mandrillus, Papio and Miopithecus), and in some cases it assumes a "plunger-like" morphology (e.g., in Lagothrix and Ateles; Fig. 11). The comparative functional anatomy and phylogenetic variability of the striated penile muscles in primates would certainly repay further study. 


\section{The Female Genitalia and Cryptic Female Choice}

In 1996, William Eberhard expressed the view that "many evolutionary biologists have underestimated the possibilities for cryptic female choice." He also noted that "cryptic choice does not even appear in the indices of recent major books on sexual selection." Matters have improved during the intervening years, primarily due to the efforts of researchers who work on insects and other invertebrates. Where mammals are concerned, however, progress has been much slower. This is partly a result of the practical difficulties inherent in conducting experiments on mammals. However, it is also the case that some mammalian reproductive biologists have largely ignored the topic of postcopulatory sexual selection.

When male galagos, baboons or chimpanzees engage in copulation, it is the female's reproductive anatomy and physiology that will determine whether or not their sperm survive; only a small fraction of them will reach the oviduct. Once this is acknowledged, it is logical to ask whether the female's anatomy and physiology might positively, or negatively, bias the fate of spermatozoa that originate from different males and, if so, how? For example, if one male possesses a more advantageous penile morphology, or copulatory pattern, or a biochemically more advantageous mixture of accessory glandular secretions, then might the female's reproductive system preferentially receive and transport his spermatozoa? It is also the female's reproductive system that triggers a number of processes during sperm transport (e.g., capacitation, hyperactivation and the acrosome reaction) that are essential preludes to achieving fertilization. There are indeed many possibilities for cryptic female choice, some of which are discussed below.

The greater complexity of penile morphology in polygynandrous primates, described above in relation to sperm competition pressure (Fig. 7) is also consistent with effects of sexual selection by cryptic female choice [Dixson, 1987, 2009]. Yet, it should be kept in mind that some penile traits that benefit males might actually conflict with the female's interests [Arnqist and Rowe, 2005]. For example, the large penile spines that assist male galagos to prolong intromission might damage the female's genitalia in the process. Thus, sexual conflict adds another layer of complexity to discussions of genital coevolution and copulatory behaviour.

Coevolution between the sexes certainly does occur in a positive way, for whatever conflicts might arise between the 2 sexes, a close fit between complementary genital structures is essential if copulation is to succeed. Thus, erect penile length correlates closely with vaginal length in primates, at least in the small number of species for which I have been able to obtain measurements [Dixson, 2009, 2012]. The ability of males to place ejaculates as closely as possible to the female's os cervix is crucial, as by doing so they improve the chances that sperm will survive and gain access to the cervical canal and uterus. In this context, a potential conflict arises in those species where females have large, projecting sexual skin swellings, as these effectively extend the distance that males must negotiate during mating. This is the case, for example, in the chimpanzee, in which the operating depth of the vagina increases by $50 \%$ at midcycle (Fig. 12). Male chimpanzees probably vary in their ability to position their copulatory plugs near the cervix [Dixson and Mundy, 1994]. Thus, although female swellings have evolved primarily as sexually attractive graded signals of female fertility [Dixson, 1983; Nunn, 1999], as a secondary process cryptic female choice may also have occurred, favouring complementary elongation of the penis. This hypothesis 
Fig. 12. Measurements of the erect penis and vaginal length (at different stages of sexual skin swelling) in chimpanzees. Data are for individual animals, with means and standard deviations indicated by the histograms and bars [Dixson and Mundy, 1994].

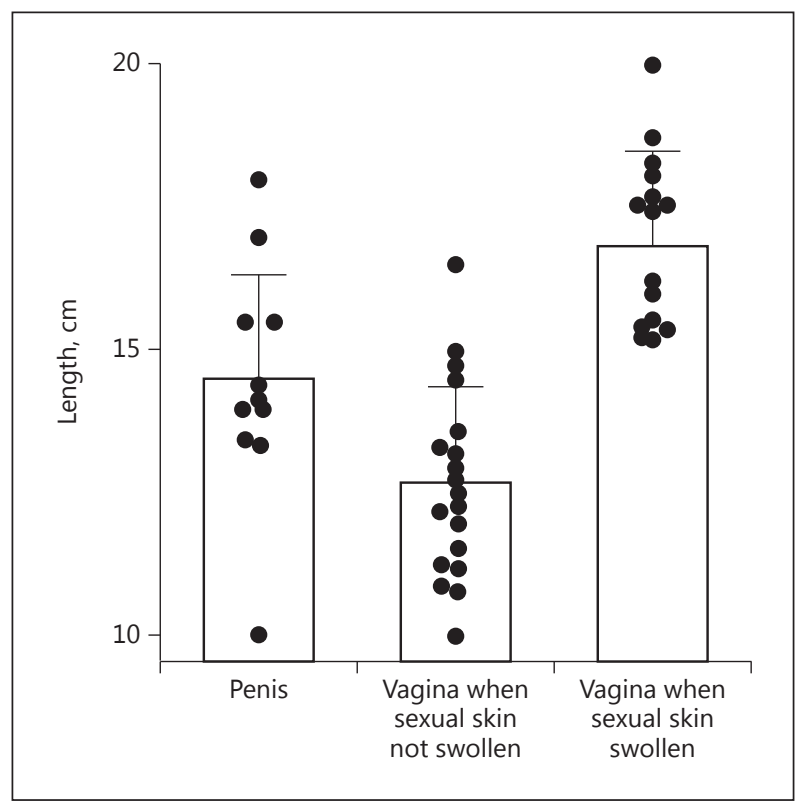

merits further testing. Unfortunately, few measurements of vaginal and penile lengths are available for those species in which females have sexual skin swellings.

Once mating is complete, sperm must survive long enough to migrate, or to be actively transported, into the cervical canal and the uterus. The vagina constitutes a potentially hostile environment for sperm, and especially so in the human female, due to its low $\mathrm{pH}$. Masters and Johnson [1966] reported that immediately after ejaculation vaginal $\mathrm{pH}$ rose to approximately 7.0 in women due to the buffering effect of seminal fluid. This increased sperm survival and motility in the vagina, an effect that lasted for several hours. It is possible, therefore, that the alkalinity of seminal vesicular secretions has undergone positive selection for this reason. As far as we know, all primates ejaculate intravaginally so that buffering of vaginal $\mathrm{pH}$ by semen might constitute a general phenomenon for the order as a whole. Some caution is advisable, however, as it transpires that human vaginal $\mathrm{pH}$ is exceptionally low, averaging 4.5 , as compared to $\mathrm{pH}$ values of 7.6 (Macaca nemestrina), 5.0-5.6 (Papio anubis), 5.5 (P. cynocephalus) and 6.5 (A. geoffroyi) at around the time of the oestrogen peak [Miller et al., 2016]. Nonetheless, in the last of the species listed (the black-handed spider monkey, A. geoffroyi), Hernández-López et al. [2008] have demonstrated positive effects of the presence of a seminal coagulum upon vaginal $\mathrm{pH}$ (increased to 7.0) and the migration of fast linearly moving sperm into the uterus following intravaginal artificial insemination procedures. They concluded that "although still far from being compelling evidence of female cryptic choice in the spider monkey, our results acknowledge that sperm selection starts as early as the vagina, where females seemingly rely on cues provided by the seminal coagulum in favouring or opposing sperm migration."

Important as motility is in ensuring that sperm survive and migrate into the cervix, it is the rhythmic contractions of the female's reproductive tract that are mainly 
responsible for transporting sperm to the oviducts. As Martin [2013] has pointed out: "When moving unaided, human sperm can swim about 7 inches per hour. At that rate it would take at least forty-five minutes to cover the distance from the neck of the womb to the lower end of the oviduct." In reality, the first cohort of spermatozoa reach the human oviduct anywhere between 5 and $68 \mathrm{~min}$ after copulation, and in less than $5 \mathrm{~min}$ in rabbits [Harper, 1994]. Peristaltic contractions of the human uterus occur continuously, and at a frequency of 2-5 times/min. However coitus (irrespective of whether a female orgasm occurs) induces the release of oxytocin in women [Carmichael et al., 1987; Komisaruk et al., 2006], and Wildt et al. [1998] have shown experimentally that administering oxytocin to women causes uterine contractions to increase in strength and frequency. Thus, it is possible that coital stimuli might enhance rapid sperm transport via this mechanism. Unfortunately there is very little information about this subject for any of the non-human primates. It is often stated that sperm conveyed to the oviducts, via the initial rapid transport phase, are damaged, or voided into the peritoneal cavity via the upper end of the oviduct. Thus, they are unlikely to fertilize ova. However, we should consider the possibility that rapid sperm transport might even favour a male chimpanzee, stump-tailed macaque or baboon that succeeds in mating last, close to ovulation. Whether such events might influence sperm competition or cryptic female choice in primates is not known.

After the rapid phase of sperm transport, there is a slower and more sustained process, during which sperm move through the uterus and the oviduct. The cervix may provide a reservoir for gradual release of these gametes, as sperm are known to enter the cervical crypts in large numbers and to remain there for varying periods $(H$. sapiens [Insler et al., 1980; Martin, 2013]; Macaca fascicularis [Jasczak and Hafez, 1972]). Oestrogen stimulates changes in the physical and chemical properties of the cervical mucus that facilitate the survival and transport of motile sperm. Gould et al. [1984] recovered human sperm from the cervical mucus (not from the crypt contents) 5 days after insemination. Fertilizing capacity was detected for up to 3 days; the upper limits for sperm survival and fertilizing ability are not known. Where nonhuman primates such as macaques and chimpanzees are concerned, access to the cervical crypts by the sperm of rival males and the differential effects of the female's physiology upon sperm survival may constitute additional mechanisms for postcopulatory sexual selection.

The process of sperm transport outlined above operates effectively in the absence of orgasm in women. Indeed, it has long been appreciated that women who are anorgasmic exhibit normal fertility [Dickinson, 1949]. Despite claims to the contrary [e.g., Baker and Bellis, 1995], there is no convincing evidence of a role for female orgasm in postcopulatory sexual selection in human beings or in other primates [Lloyd, 2005; Dixson, 2009, 2012]. Equally problematic is an attempt to link female orgasm with the evolution of induced ovulation among mammals [Pavlicev and Wagner, 2016]. These authors posit that female orgasm functioned in ancestral mammals to induce ovulation, but with the later advent of spontaneous ovulation "orgasm was freed to gain secondary roles." A full critique of this hypothesis is beyond the scope of the current review. However, it is relevant to note that female orgasm probably has nothing to do with induced ovulation and that it is more likely to represent the homologue of the male's ejaculatory response [Symons, 1979; Lloyd 2005]. It is interesting that PET scan studies have shown that manual stimulation of the penis (resulting in ejaculation) or the clitoris (resulting in orgasm) activates exactly the same areas of the brain 


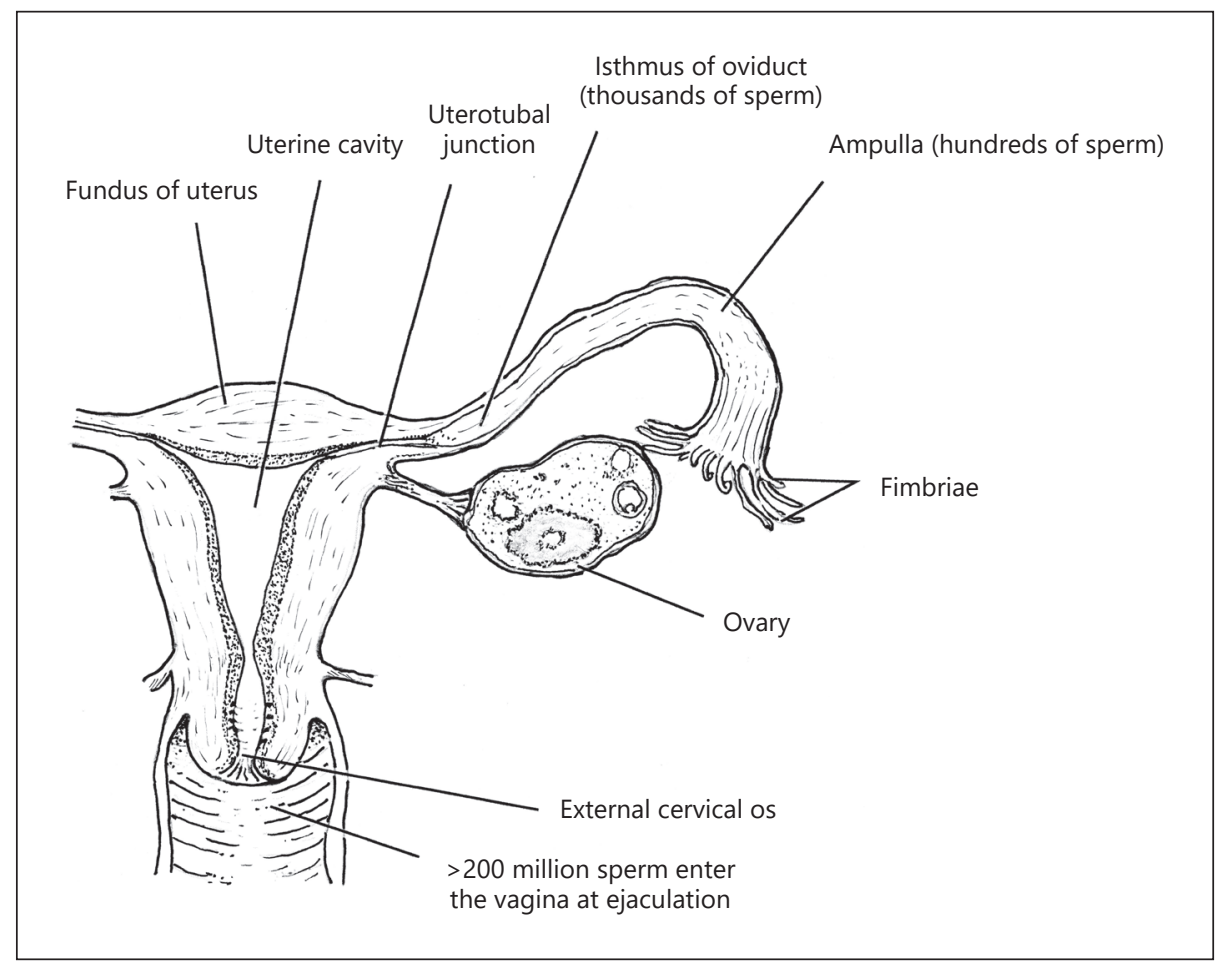

Fig. 13. The human female reproductive tract and postcoital sperm numbers recorded at various levels within the tract [Dixson, 2009].

(in the dorsolateral and ventrolateral pontine tegmentum) in men and women [Huynh et al., 2013]. This recalls Frank Beach's [1976] observation that neural mechanisms mediating sexual patterns typical of one sex may also be capable of expression in the opposite sex, given favourable circumstances for their elicitation. On that basis, Donald Symons [1979] was probably correct when he interpreted female orgasm as being a "byproduct of female bisexual potential."

Given that many millions of spermatozoa are deposited in the vagina at ejaculation, it is remarkable that only a few hundreds or thousands of them are recoverable from the oviduct. In sheep, for example, 600-700 sperm may be found in the oviduct, out of the 8,000 million released at ejaculation. Human sperm counts are much lower than this so that 280 million sperm are released initially, but only about 200 may be recoverable, at any one time, from the ampulla of the oviduct [Harper, 1994]. These numbers do not represent the only spermatozoa to reach the oviducts. Rather, they constitute "snapshot" counts of a transient population of sperm that is steadily replenished as the female's tract transports gametes through the uterus and uterotubal junction, to enter the oviduct (Fig. 13).

Spermatozoa do not pass freely into the oviduct; the uterotubal junction acts as a filtering mechanism in ways that differ between mammalian species and that are 
Fig. 14. Correlation between relative oviductal length and relative testes size in mammals. The sample includes mainly artiodactyls, carnivores, primates and marsupials ( $=$ Homo sapiens) [Dixson, 2012; adapted from Anderson et al., 2006].

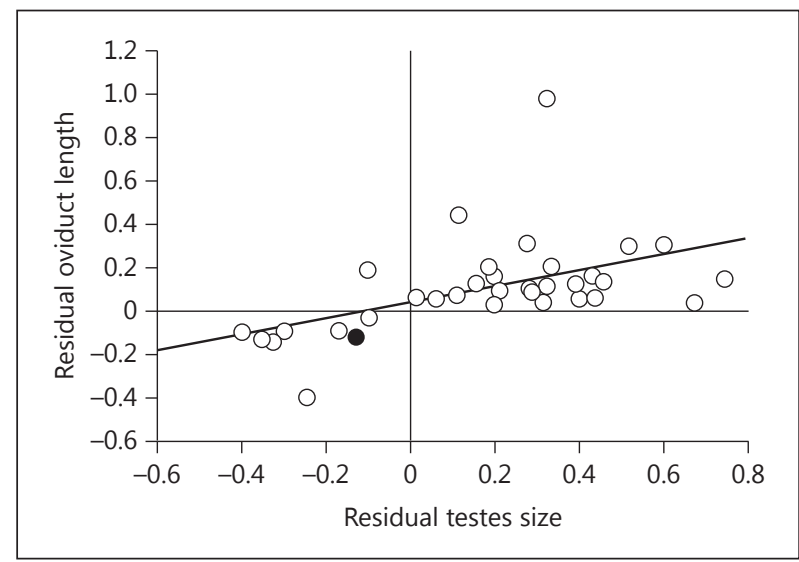

not fully understood. There is experimental evidence that the human uterotubal junction might act reflexively as a one-way valve, allowing sperm to enter the isthmus of the oviduct [Shafik, 1996]. In cattle, a vascular plexus in the wall of the junction can become filled with blood and compress the lumen, thus acting as a valve [Wrobel et al., 1993]. In the uterotubal junction of the sow, an infundibular-cornual ligament contracts rhythmically during the peri-ovulatory period. This, again, may represent a mechanism for filtering or transporting sperm [Persson and Rodriguez-Martinez, 1990]. Normal motility can be important if sperm are to pass through the uterotubal junction (golden hamster [Smith et al., 1988]; rat [Gaddum-Rosse, 1981]). Proteins on the sperm head are also important, such as ADAM3 in the mouse [Yamaguchi et al., 2009], and sperm may attach temporarily to the uterotubal epithelium. How this occurs is not known. Where the non-human primates are concerned, there are few data on the anatomy or physiology of the uterotubal junction; comparative studies are badly needed in this area.

After they have passed through the uterotubal junction, sperm continue to interact in complex ways with the physical and chemical environment provided by the female reproductive tract. In the lower oviduct (the isthmus), sperm become attached to its epithelium. This process has been studied in domesticated mammals (e.g., cattle, sheep and pigs) but very little is known concerning sperm-oviductal interactions in most of the 5,400+ species of mammals, including the non-human primates. In cattle, for example, seminal plasma proteins, on the surface of the sperm acrosome, bind to fucose-containing ligands on cilia lining the isthmus. A reservoir of gametes is thus produced; their viability is enhanced and they undergo important changes (capacitation and flagellar hyperactivation) that prepare them to reach the upper oviduct, and fertilize ova [for reviews, see Suarez, 2007, 2010]. Unfortunately, we still know very little about interactions between the oviducts and spermatozoa in primates. Consider, for example, a female chimpanzee that mates with multiple partners prior to ovulation. Do spermatozoa from all of these males succeed in binding to cells in the isthmus of the oviduct? If so, are the gametes of some males more successful than others in undergoing capacitation and hyperactivation? Are some sperm more successful in disengaging from the epithelia of the storage site and ascending the oviduct to encounter the ovum? There are currently no answers to these questions. 
Experiments have shown that in the domestic pig, differential activation or suppression of motility in subpopulations of sperm within the isthmus may play a key role in sperm selection [Sakate et al., 2006]. The oviduct is increasingly recognized as being a crucial arena for mammalian sperm competition and cryptic female choice [e.g., Holt and Fazeli, 2010]. In this regard, it is interesting that the oviducts of mammals differ considerably in length, in relation to body size [Hunter, 1988]. Careful measurements of the (extramural) length of the oviduct in 48 species, representing 33 genera of mammals [Anderson et al., 2006], have shown that residuals of oviduct length are positively correlated with relative testes sizes (Fig. 14) and also with sperm midpiece volumes. In addition to anatomical specializations, the oviduct may possess genetic mechanisms for filtering and screening spermatozoa. In mice, for example, it has been shown that spermatozoa trigger a number of changes in the oviductal transcriptome [Fazeli et al., 2004]. Elegant experiments involving bilateral laparoscopic insemination of either X or Y chromosome-bearing sperm into the oviducts of pigs have demonstrated that certain genomic responses are sex specific [Almiñana et al., 2014]. These authors suggest that such sex-specific oviductal responses to spermatozoa might represent "a gender biasing mechanism controlled by the female." If correct, this would provide a physiological basis for theories that seek to explain the existence of adaptive skewing of birth sex ratios in mammals (e.g., that healthy/highranking females might benefit from producing more sons [Trivers and Willard, 1973]). Skewing of birth sex ratios has been reported for a number of mammals [Clutton-Brock and Iason, 1986]. However, the strength and importance of such effects remain debatable, especially where the primates are concerned. Brown and Silk [2002] examined possible effects of maternal rank upon primate birth sex ratios; their meta-analysis employed 35 data sets derived from studies of macaques, baboons, spider monkeys, capuchins and chimpanzees. This showed that there were no effects of female rank upon the sex of their offspring and that previously reported skewing effects were due to statistical artefacts arising from the use of small sample sizes.

\section{Some Final Remarks Concerning the Evolution of Human Reproduction}

This review has discussed how sexual selection, acting via sperm competition and cryptic female choice, has influenced the evolution of the reproductive systems of primates and other mammals. In conclusion, it may be useful to consider what role postcopulatory sexual selection might have played during human evolution. The sexual behaviour and reproductive physiology of our remote ancestors is, inevitably, shrouded in mystery. Yet, a good deal is known about how postcopulatory sexual selection has affected reproductive traits among the extant primates. Thus, the possibility exists to compare adaptive traits (anatomical, physiological and behavioural) exhibited by various non-human primates with their human homologues. As an example, chimpanzees and bonobos exhibit very low frequencies of abnormal (pleiomorphic) sperm $(<5 \%)$ in the ejaculate, whereas human semen contains a large proportion (approx. 27\%) of morphologically abnormal gametes, as is also the case in the gorilla [Seuánez, 1980]. There is an inverse relationship between relative testes size, sperm competition pressures and numbers of abnormal sperm in the ejaculates of humans and the great apes. It has been argued that it is the very absence of selection pressures relating to sperm competition which allows abnormal sperm to persist 
in humans and gorillas [Dixson, 2009, 2012]. The same may be true for the eusocial naked mole rat, Heterocephalus glaber [van der Horst and Maree, 2014].

Below are 10 further examples of traits that have undergone positive selection, via sperm competition and/or cryptic female choice in polygynandrous primates and in other mammals where multiple-partner matings are the norm:

1 Large testes relative to male body size

2 Faster rates of spermatogenesis

3 Greater capacity to sustain high sperm counts

4 Sperm with larger midpiece volumes

5 More muscular vasa deferentia

6 Large seminal vesicles and prostate glands relative to body size

7 More pronounced seminal coagulation/copulatory plug formation

8 Higher copulatory frequencies

9 Morphologically more complex penes

10 Longer oviducts in relation to female body size

Here, in summary, is the situation concerning the same 10 traits in human beings:

1 Human testes are smaller than predicted in relation to body weight, and especially so in some Asiatic populations (Fig. 2)

2 Men produce 4.4 million sperm each day per gramme of testicular parenchyma, slower than in any other mammal measured [Sharpe, 1994]. The rate for the rhesus macaque is $23 \mathrm{million} / \mathrm{g}$. Seminiferous epithelium cycle lengths are longer in human beings than in other primates so far measured, including macaques and chimpanzees [Ramm and Stockley, 2010]

3 In the human male, repeated ejaculations by men ( 3 per day) result in an $84 \%$ decline in their sperm counts over a 10-day period [Freund, 1963]. The human reproductive system is not adapted to sustain high sperm counts during periods of high sexual activity. Even after repeated ejaculations ( 6 times over $5 \mathrm{~h}$ ) sperm counts in the chimpanzee greatly exceed those of human males [Marson et al., 1989]

4 Human sperm have smaller midpiece volumes than any of the 40 primate species measured by Anderson et al. [2005], with the exception of the common marmoset

5 In polygynandrous mammals, the ratio of the vas deferens muscle wall thickness to lumen diameter averages $9.9 \pm 0.7$, as compared to $6.8 \pm 0.6$ in genera having monogamous or polygynous mating systems $(p<0.01)$. The ratio in human beings (6.31) is typical of monogamous and polygynous taxa [Anderson et al., 2004]

6 The human seminal vesicles are relatively small. The prostate gland is not especially large [Dixson, 1998; Anderson and Dixson, 2009]

7 Human semen exhibits a low level of coagulation after ejaculation. There is no distinct coagulum or copulatory plug [Dixson and Anderson, 2002]

8 Large-scale surveys of married couples (in the USA, UK and China) indicate that intercourse occurs 2-4 times per week on average [Kinsey et al., 1948; Wellings et al., 1994; Liu et al., 1997]. Copulatory frequencies are significantly higher in polygynandrous primates than in monogamous/polygynous taxa, including $H$. sapiens [Dixson, 1995b]

9 Human phallic morphology is not unusual, except for its girth, and even that is not unique among primates [Dixson, 2009, 2012] 
10 Residuals of oviduct length correlate with residual testes sizes in mammals, indicating possible effects of postcopulatory sexual selection upon the length of the oviduct. However, women have relatively short oviducts (Fig. 14)

Taken as a whole, the above comparisons indicate that it is most unlikely that postcopulatory sexual selection could have played a significant role in the evolution of the human reproductive system. Worldwide, most human societies engage in polygynous or monogamous marriages. In $84 \%$ of 185 societies considered by Ford and Beach [1951] "men are permitted by custom to have more than one mate at a time if they can arrange to do so." In practice, most men cannot "arrange to do so," due to cultural constraints, or to lack of status and resources. Monogamous marriages are the norm, therefore. Human beings thus display a variety of reproductive traits that are consistent with a primarily monogamous or polygynous ancestry [Dixson, 2009]. Even if an example should come to light of a human population in which polygynandrous mating and sperm competition occurs, this would still represent the exception, rather than the rule, where human sexual behaviour is concerned.

\section{Disclosure Statement}

The author confirms that there are no conflicts of interest involved in publishing this work.

\section{References}

Almiñana C, Caballero I, Heath PR, Maleki-Dizaji S, Parrilla I, Cuello, C, Gil MA, Vazquez JL, Vazquez JM, Roca J, Martinez EA, Holt WV, Fazeli A (2014). The battle of the sexes starts in the oviduct: modulation of oviductal transcriptome by X and Y-bearing spermatozoa. BMC Genomics 15: 293. http://www.biomedcentral.com/1471-2164/15/293.

Anderson MJ, Dixson AF (2002). Sperm competition: mobility and the midpiece in primates. Nature 416: 496.

Anderson MJ, Dixson AF (2009). Sexual selection affects the sizes of the mammalian prostate gland and seminal vesicles. Current Zoology 55: 1-8.

Anderson MJ, Chapman SJ, Videan EN, Evans E, Fritz J, Stoinski TS, Dixson AF, Gagneux P (2007). Functional evidence for differences in sperm competition in humans and chimpanzees. American Journal of Physical Anthropology 134: 274-280.

Anderson MJ, Dixson AS, Dixson AF (2006). Mammalian sperm and oviducts are sexually selected: evidence for co-evolution. Journal of Zoology 270: 682-668.

Anderson MJ, Nyholt J, Dixson AF (2004). Sperm competition affects the structure of the mammalian vas deferens. Journal of Zoology 264: 97-103.

-Anderson MJ, Nyholt J, Dixson AF (2005). Sperm competition and the evolution of sperm midpiece volume in mammals. Journal of Zoology 267: 135-142.

Arnqist G, Rowe L (2005). Sexual Conflict. Monographs in Behavior and Ecology. Princeton, Princeton University Press.

Baker RR, Bellis MA (1995). Human Sperm Competition. London, Chapman \& Hall.

Barelli C, Matsudaira K, Wolf T, Roos C, Heistermann M, et al. (2013). Extra-pair paternity confirmed in white-handed gibbons. American Journal of Primatology 75: 1185-1195.

Beach FA (1976). Sexual attractivity, proceptivity and receptivity in female mammals. Hormones and Behavior 7: 105-138.

Beach FA, Levinson G (1950). Effects of androgen on the glans penis and mating behavior of castrated rats. Journal of Experimental Biology 114: 159-171.

Bedford JM, Hoskins DD (1990). The mammalian spermatozoon: morphology, biochemistry and physiology. In Marshall's Physiology of Reproduction (GE Lamming, ed.), vol 2: Reproduction in the Male, pp 379-568. Edinburgh, Churchill Livingstone.

Bradley BJ, Robbins MM, Williamson EA, Steklis HD, Steklis NG, Eckhardt N, Boesch C, Vigilant L (2005). Mountain gorilla tug-of-war: silverbacks have limited control over reproduction in multimale groups. Proceedings of the National Academy of Sciences of the United States of America 102: 9418-9423. 
Breed WG (1981). Unusual anatomy of the male reproductive tract in Notomys alexis (Muridae). Journal of Mammalogy 62: 373-375.

Brindle M, Opie C (2016). Postcopulatory sexual selection influences baculum evolution in primates and carnivores. Proceedings of the Royal Society B: Biological Sciences 283: 20161736.

Brown GR, Silk JB (2002). Reconsidering the null hypothesis: is maternal rank associated with birth sex ratios in primate groups? Proceedings of the National Academy of Sciences of the United States of America 99: 11252-11255.

Campbell CJ (2007). Primate sexuality and reproduction. In Primates in Perspective (Campbell CJ, Fuentes A, Mackinnon KC, Panger M, Bearder SK, eds.), pp 423-437. New York, Oxford University Press.

Carmichael MS, Humbert R, Dixen J, Palmisano G, Greenleaf W, Davidson JM (1987). Plasma oxytocin increases in human sexual response. Journal of Clinical Endocrinology and Metabolism 64: 27-31.

Clutton-Brock TH, Iason GR (1986). Sex ratio variation in mammals. Quarterly Review of Biology 61: $339-374$

Cummins J (2010). Sperm motility and energetics. In Sperm Biology: An Evolutionary Perspective (Birkhead TR, Hosken DJ, Pitnik S, eds.), pp 185-206. San Diego, Elsevier/Academic Press.

Dewsbury DA, Hodges AW (1987). Copulatory behavior and related phenomena in spiny mice (Acomys cahirinus) and hopping mice (Notomys alexis). Journal of Mammalogy 69: 49-57.

Dickinson RL (1949). Human Sex Anatomy. New York, Kreiger.

Dixson AF (1983). Observations on the evolution and behavioural significance of sexual skin in female primates. Advances in the Study of Behavior 13: 63-106.

Dixson AF (1987). Observations on the evolution of the genitalia and copulatory behaviour in male primates. Journal of Zoology 213: 423-443.

Dixson AF (1991). Penile spines affect copulatory behaviour in a primate (Callithrix jacchus). Physiology and Behavior 49: 557-562.

Dixson AF (1995a). Sexual selection and the evolution of copulatory behaviour in nocturnal prosimians. In Creatures of the Dark: The Nocturnal Prosimians (Alterman L, Doyle GA, Izard MK, eds.), pp 93-118. New York, Plenum Press.

Dixson AF (1995b). Sexual selection and ejaculatory frequencies in primates. Folia Primatologica 64: $146-152$.

Dixson AF (1997). Evolutionary perspectives on primate mating systems and behavior. Annals of the New York Academy of Sciences 807: 42-61.

Dixson AF (1998). Sexual selection and the evolution of the seminal vesicles in primates. Folia Primatologica 68: 300-306.

Dixson AF (2009). Sexual Selection and the Origins of Human Mating Systems. Oxford, Oxford University Press.

Dixson AF (2012). Primate Sexuality: Comparative Studies of the Prosimians, Monkeys, Apes, and Humans, 2nd ed. Oxford, Oxford University Press.

Dixson AF, Anderson MJ (2002). Sexual selection, seminal coagulation and copulatory plug formation in primates. Folia Primatologica 73: 63-69.

Dixson AF, Mundy NI (1994). Sexual behavior, sexual swelling and penile evolution in chimpanzees (Pan troglodytes). Archives of Sexual Behavior 23: 267-280.

Dixson AF, Nyholt J, Anderson MJ (2004a). A positive relationship between baculum length and prolonged intromission patterns in mammals. Acta Zoologica Sinica 50: 490-503.

Dixson AF, Pissinatti A, Anderson MJ (2004b). Observations on genital morphology and anatomy of a hybrid male muriqui (genus Brachyteles). Folia Primatologica 75: 61-69.

Dorus S, Evans PD, Wyckoff GJ, Choi SS, Lahn BT (2004). Rate of molecular evolution of the seminal gene SEMG2 correlates with levels of female promiscuity. Nature Genetics 36: 1326-1329.

Driller C, Perwitasari-Farajallah D, Zischler H, Merker S (2009). The social system of Lariang tarsiers (Tarsius lariang) as revealed by genetic analyses. International Journal of Primatology 30: 267-281.

Eberhard WG (1985). Sexual Selection and Animal Genitalia. Cambridge, Harvard University Press.

Eberhard WG (1996). Female Control: Sexual Selection by Cryptic Female Choice. Princeton, Princetown University Press.

Eberhard WG (2009). Postcopulatory sexual selection: Darwin's omission and its consequences. Proceedings of the National Academy of Sciences of the United States of America 106(suppl 1): 10025-10032.

Eberle M, Kappeler PM (2004). Selected polyandry, female choice and inter-sexual conflict in a small nocturnal solitary primate (Microcebus murinus). Behavioral Ecology and Sociobiology 57: 91-100.

Fazeli A, Affara NA, Hubank M, Holt WV (2004). Sperm-induced modification of the oviductal gene expression profile after natural insemination in mice. Biology of Reproduction 71: 60-65.

Fietz J, Zischler H, Schweig KC, Tomiuk JD, Dausmann KH, et al. (2000). High rates of extra-pair young in the pair-living fat-tailed dwarf lemur, Cheirogaleus medius. Behavioral Ecology and Sociobiology 49: 8-17.

Ford CS, Beach FA (1951). Patterns of Sexual Behavior. New York, Harper \& Rowe. 
Freund M (1963). Effect of frequency of emission on semen output and an estimate of daily sperm production in man. Journal of Reproduction and Fertility 6: 269-286.

Gaddum-Rosse P (1981). Some observations on sperm transport through the uterotubal junction of the rat. American Journal of Anatomy 160: 333-341.

Gage MJG, Freckleton R (2003). Relative testis size and sperm morphometry across mammals: no evidence for an association between sperm competition and sperm length. Proceedings of the Royal Society of London B: Biological Sciences 270: 625-632.

Gallup GG Jr, Burch RL, Zappieri ML, Parvez RA, Stockwell ML, Davis JA (2003). The human penis as a semen displacement device. Evolution and Human Behavior 24: 277-289.

Gomendio M, Roldan ERS (1991). Sperm size and sperm competition in mammals. Proceedings of the Royal Society of London B: Biological Sciences 243: 181-185.

Gomendio M, Roldan ERS (2008). Implications of diversity in sperm size and function for sperm competition and fertility. International Journal of Developmental Biology 52: 439-447.

Gould JE, Overstreet JW, Hanson FW (1984). Assessment of human sperm function after recovery from the female reproductive tract. Biology of Reproduction 31: 888-894.

Greer WE, Roussel JD, Austin CR (1968). Prevention of coagulation in monkey semen by surgery. Journal of Reproduction and Fertility 15: 153-155.

Grützner F, Nixon B, Jones RC (2008). Reproductive biology in egg-laying mammals. Sexual Development 2: 115-127.

-Hanby JP, Robertson LT, Phoenix CH (1971). The sexual behavior of a confined troop of Japanese macaques. Folia Primatologica 16: 123-143.

-Harcourt AH, Gardiner J (1994). Sexual selection and genital anatomy of male primates. Proceedings of the Royal Society of London B: Biological Sciences 255: 47-53.

Harcourt AH, Harvey PH, Larson SG, Short RV (1981). Testis weight, body weight and breeding system in primates. Nature 293: 55-57.

Harper MJK (1994). Gamete and zygote transport. In The Physiology of Reproduction (Knobil E, Neill JD, eds.), 2nd ed., vol 1, pp 123-187. New York, Raven Press.

Hart BL, Melese-d'Hospital P (1983). Penile mechanisms and the role of the striated penile muscles in penile reflexes. Physiology and Behavior 31: 807-813.

Hergenrother S (2015). Evolution of Prostate Specific Gene Expression Associated with Postcopulatory Sexual Selection. PhD dissertation, Duquesne University, Pittsburgh.

Hernández-López L, Cerda-Molina AL, Páez-Ponce DL, Mondragón-Ceballos R (2008). The seminal coagulum favors passage of fast-moving sperm into the uterus in the black-handed spider monkey. Reproduction 136: 411-421.

Hershkovitz P (1993). Male external genitalia of the non-prehensile tailed South American monkeys. 1. Subfamily Pithecinae, family Cebidae. Fieldiana Zoology 73: 1-17.

Holt WV, Fazeli AF (2010). The oviduct as a complex mediator of mammalian sperm function and selection. Molecular Reproduction and Development 77: 934-943.

Holt WV, Hernandez M, Warrell L, Sakate N (2010). The long and the short of sperm selection in vitro and in vivo: swim-up techniques select for the longer and faster swimming mammalian sperm. Journal of Evolutionary Biology 23: 598-608.

Huck M, Fernandez-Duque E, Babb P, Schurr T (2014). Correlates of genetic monogamy in socially monogamous mammals: insights from Azara's owl monkeys. Proceedings of the Royal Society of London B: Biological Sciences 281: 20140195.

Hunter RHF (1988). The Fallopian Tubes: Their Role in Fertility and Infertility. Berlin, Springer.

Huynh HK, Willemsen ATM, Lovick TA, Holstege G (2013). Pontine control of ejaculation and female orgasm. Journal of Sexual Medicine 10: 3038-3048.

Insler V, Glezerman M, Zeidel L, Bernstein D, Misgav N (1980). Sperm storage in the human cervix: a quantitative study. Fertility and Sterility 33: 288-293.

Jasczak S, Hafez ESE (1972). The cervix uteri and sperm transport in female macaques. In Medical Primatology: Proceedings of the Third Conference on Experimental Medicine and Surgery (Goldsmith EL, Moor-Jankowski J, eds.), pp 263-270. Basel, Karger.

Jensen-Seaman MI, Li WH (2003). Evolution of the hominid semenogelin genes, the major proteins of ejaculated semen. Journal of Molecular Evolution 57: 261-270.

Kappeler PM (1997). Intra-sexual selection and testis size in strepsirhine primates. Behavioral Ecology 8: $10-19$.

Kelly DA (2000). Anatomy of the baculum-corpus cavernosum interface in the Norway rat (Rattus norvegicus) and implications for force transfer during copulation. Journal of Morphology 244: 69-77.

Kinsey AC, Pomeroy WB, Martin CE (1948). Sexual Behavior in the Human Male. Philadelphia, Saunders. Komisaruk B R, Beyer-Flores C, Whipple B (2006). The Science of Orgasm. Baltimore, Johns Hopkins University Press.

Koyama N (1988). Mating behavior of ring-tailed lemurs (Lemur catta) at Berenty, Madagascar. Primates 29: $163-175$. 
Lewis RJ (2009). Chest staining variation as a signal of testosterone levels in male Verreaux's sifaka. Physiology and Behavior 96: 586-592.

Liu D, Ng ML, Zhou LP, Haeberle EJ (1997). Sexual Behavior in Modern China. New York, Continuum.

Lloyd EA (2005). The Case of the Female Orgasm: Bias in the Science of Evolution. Cambridge, Harvard University Press.

Lüpold S, Linz GM, Rivers JW, Westneat DF, Birkhead TR (2009). Sperm competition selects beyond relative testes size in birds. Evolution 63: 391-402.

Marson J, Gervais D, Cooper RW, Jouannet P (1989). Influence of ejaculation frequency on semen characteristics in chimpanzees (Pan troglodytes). Journal of Reproduction and Fertility 85: 43-50.

Martin RD (2013). How We Do It: The Evolution and Future of Human Reproduction. New York, Basic Books.

Masters WH, Johnson VE (1966). Human Sexual Response. London, Churchill.

McGill TE, Coughlin RC (1970). Ejaculatory reflex and luteal activity induction in Mus musculus. Journal of Reproduction and Fertility 21: 215-220.

Miller EA, Beasely DE, Dunn RR, Archie EA (2016). Lactobacilli dominance and vaginal pH: why is the human vaginal biome unique? Frontiers in Microbiology 7: 1936. DOI: 10.3389/fmicb.2016.01936.

Møller AP (1988). Ejaculate quality, testes size and sperm competition in primates. Journal of Human Evolution 17: 479-488.

Møller AP (1989). Ejaculate quality, testes size and sperm production in mammals. Functional Ecology 3 : 91-96.

Moore HDM, Dvoráková K, Jenkins N, Breed WG (2002). Exceptional sperm cooperation in the wood mouse. Nature 418: 174-177.

Nekaris KAI (2003). Observations on mating, birthing and parental care in three taxa of slender loris in India and Sri Lanka (Loris tardigradus and Loris lydekkerianus). Folia Primatologica 74(suppl): 312-336.

Nishimura A (1988). Mating behavior of woolly monkeys, Lagothrix lagotricha, at La Macarena, Colombia. Field Studies of New World Monkeys 1: 19-27.

Nunn CL (1999). The evolution of exaggerated sexual swellings in female primates and the graded-signal hypothesis. Animal Behaviour 58: 229-246

Orr TJ, Brennan PLR (2016). All features great and small: the potential roles of the baculum and penile spines in mammals. Integrative and Comparative Biology 56: 635-643.

- Parga JA (2003). Copulatory plug displacement evidences sperm competition in Lemur catta. International Journal of Primatology 24: 889-899.

Parker GA (1970). Sperm competition and its evolutionary consequences in the insects. Biological Reviews 45: 525-567.

Parker GA (1998). Sperm competition and the evolution of ejaculates: towards a theory base. In Sperm Competition and Sexual Selection (Birkhead TR, Møller AP, eds.), pp 3-54. San Diego, Academic Press.

Parker GA (2016). The evolution of expenditure on testes. Thomas Henry Huxley Review. Journal of Zoology 298: 3-19.

Pavlicev M, Wagner G (2016). The evolutionary origin of female orgasm. Journal of Experimental Zoology Part B: Molecular and Developmental Evolution 326: 326-337.

-Persson E, Rodriguez-Martinez H (1990). The ligamentum infundibulo-cornuale in the pig: morphological and physiological studies of the smooth muscle component. Acta Anatomica 138: 111-120.

Pope TR (1990). The reproductive consequences of male cooperation in the red howler monkey: paternity exclusion in multi-male and single-male troops using genetic markers. Behavioral Ecology and Sociobiology 27: 439-446.

Prins GS, Zaneveld LJD (1980). Radiographic study of fluid transport in the rabbit vas deferens during sexual rest and after sexual activity. Journal of Reproduction and Fertility 58: 311-319.

- Pullen SL, Bearder SK, Dixson AF (2000). Preliminary observations on sexual behavior and the mating system in free-ranging lesser galagos (Galago moholi). American Journal of Primatology 51: 79-88.

Ramm SA, Stockley P (2010). Sperm competition and sperm length influence the rate of mammalian spermatogenesis. Biology Letters 6: 219-221.

Ramm SA, Parker GA, Stockley P (2005). Sperm competition and the evolution of male reproductive anatomy in rodents. Proceedings of the Royal Society London B: Biological Sciences 272: 949-955.

Reno PL, McLean CY, Hines JE, Capellini TD, Bejerano G, Kingsley DM (2013). A penile spine/vibrissa enhancer sequence is missing in modern and extinct humans but is retained in multiple primates with penile spines and sensory vibrissae. PLoS One 8: e84258.

Rodriquez-Sierra JF, Crowley WR, Komisaruk BR (1975). Vaginal stimulation in rats induces prolonged lordosis responsiveness and sexual receptivity. Journal of Comparative and Physiological Psychology 89: 79-85.

Sachs BD (1983). Potency and fertility: hormonal and mechanical causes and effects of penile actions in rats. In Hormones and Behaviour in Higher Vertebrates (Balthazart J, Prove E, Gilles R, eds.), pp 86-110. Berlin, Springer. 
Sakate N, Elliott RMA, Watson PF, Holt WV (2006). Sperm selection and competition in pigs may be mediated by differential motility activation and suppression of sperm subpopulations within the oviduct. Journal of Experimental Biology 209: 1560-1572.

Schülke O, Kappeler PM, Zischler H (2004). Small testes size despite extra-pair paternity in the pair-living nocturnal primate Phaner furcifer. Behavioral Ecology and Sociobiology 55: 293-301.

-Schultz NG, Lough-Stevens M, Abreu E, Orr T, Dean MD (2016). The baculum was gained and lost multiple times during mammalian evolution. Integrative Comparative Biology 56: 635-643.

-Seuánez HN (1980). Chromosomes and spermatozoa of the African great apes. Journal of Reproduction and Fertility Supplement 28: 91-104.

Shafik A (1996). Study of the intramural oviduct response to tubal and uterine distension: identification of tubo-uterine sphincter and reflex. Human Reproduction 11: 2527-2530.

Sharpe RM (1994). Regulation of spermatogenesis. In The Physiology of Reproduction (Knobil E, Neill JD, eds.), 2nd ed., vol 1, pp 1363-1434. New York, Raven Press.

Short RV (1979). Sexual selection and its component parts, somatic and genital selection, as illustrated by man and the great apes. Advances in the Study of Behavior 9: 131-158.

Simmons LW, Firman RC (2014). Experimental evidence for the evolution of the mammalian baculum by sexual selection. Evolution 68: 276-283.

Smith RL (1984). Human sperm competition. In Sperm Competition and the Evolution of Animal Mating Systems (Smith RL, ed.), pp 601-659. New York, Academic Press.

-Smith TT, Koyanagi F, Yanagimachi R (1988). Quantitative comparison of the passage of homologous and heterologous spermatozoa through the uterotubal junction of the golden hamster. Gamete Research 19: 227-234.

Stockley P (2002). Sperm competition risk and male genital anatomy: comparative evidence for reduced duration of female sexual receptivity in primates with penile spines. Evolutionary Ecology 16: 123137.

Stockley P, Ramm SA, Sherborne AL, Thom MDF, Paterson S, Hurst JL (2013). Baculum morphology predicts reproductive success of male house mice under sexual selection. BMC Biology 11: 66 .

Suarez SS (2007). Interactions of spermatozoa with the female reproductive tract: inspiration for assisted reproduction. Reproduction Fertility and Development 19: 103-110.

Suarez SS (2010). How do sperm get to the egg? Bioengineering expertise needed! Experimental Mechanics 50: 1267-1274.

Suarez SS, Marquez B, Harris TP, Schimenti JC (2007). Different regulatory systems operate in the midpiece and principal piece of the mammalian sperm flagellum. Society of Reproduction and Fertility Supplement 65: 331-334.

Symons D (1979). The Evolution of Human Sexuality. Oxford, Oxford University Press.

Taggart DA, Johnson JL, O’Brien HP, Moore HDM (1993). Why do spermatozoa of American marsupials form pairs? A clue from the analysis of sperm-pairing in the epididymis of the grey short-tailed possum, Monodelphis domestica. Anatomical Record 236: 465-478.

Thornhill R (1983). Cryptic female choice and its implications in the scorpionfly Harpobittacus nigriceps. American Naturalist 122: 765-788.

Trivers R (1985). Social Evolution. Menlo Park, Benjamin/Cummings.

Trivers R, Willard DE (1973). Natural selection of parental ability to vary the sex ratio of offspring. Science 179: 90-92.

van der Horst G, Maree L (2014). Sperm form and function in the absence of sperm competition. Molecular Reproduction and Development 81: 204-216.

Wellings K, Field J, Johnson AM, Wadsworth J (1994). Sexual Behaviour in Britain: The National Survey of Sexual Attitudes and Lifestyles. London, Penguin Books.

Wickings EJ, Dixson AF (1992). Testicular function, secondary sexual development and social status in male mandrills (Mandrillus sphinx). Physiology and Behavior 52: 909-916.

-Wildt L, Kissler S, Licht P, Becker W (1998). Sperm transport in the human female genital tract and its modulation by oxytocin as assessed by hysterosalpingoscintigraphy, hysterotonography, electrohysterography and Doppler sonography. Human Reproduction Update 4: 655-666.

Wrobel K-H, Kujat R, Fehle G (1993). The bovine tubouterine junction: general organization and surface morphology. Cell and Tissue Research 271: 227-239.

Yamaguchi R, Muro Y, Isotani A, Tokuhiro K, Takumi K, Adham I, Ikawa M, Okabe M (2009). Disruption of ADAM3 impairs the migration of sperm into oviduct in mouse. Biology of Reproduction 81: $142-146$.

Yanagimachi R (1994). Mammalian fertilization. In The Physiology of Reproduction (Knobil E, Neill JD, eds.), 2nd ed., vol 1, pp 189-317. New York, Raven Press.

Zhou T, Wang G, Chen M, Zhang M, Guo Y, Yu C, Zhou Z, Si W, Sha J, Guo X (2015). Comparative analysis of macaque and human sperm proteomes: insights into sperm competition. Proteomics 15: 1564-1573. 